\title{
El dilema corporativo del comunalismo forestal
}

\author{
Claudio Garibay
}

En el presente artículo se reflexiona sobre el impacto de la empresa forestal comunitaria en la transformación del orden social de la comunidad campesina indígena tradicional. En el orden material se analiza la transformación de una economía centrada en el núcleo familiar hacia otra de carácter colectivista y de alcance aldeano. En el orden de la reciprocidad social se verá la transformación de una modalidad liberal en una corporada; $y$ en el orden político la evolución hacia un autogobierno centralizado y un poder fuerte. Este proceso de transformación se ilustra con el asombroso caso de la comunidad de San Pedro el Alto, población de ascendencia zapoteca ubicada en la Sierra Sur de Oaxaca.

PALABRAS CLAVE: comunalismo forestal, sociedad campesina, corporativismo, economía aldeana, ethos comunitario, hegemonía comunal

This paper reflects on the effect that communal forestry ventures have on the social order of traditional indigenous peasant communities. From a material standpoint, the paper analyses the transformation of a family-oriented economy to a collectivist system that involves whole villages. In the realm of social reciprocity there's a shift from a liberal mode to a corporate one. In the political order there's an evolution towards a centralized self-government and a strong authority. This transformation process can be exemplified by the amazing case of the San Pedro el Alto Zapotec community, located on the Sierra Sur of Oaxaca.

KEY WORDS: communal forestry, peasant society, corporativism, village economy, communal ethos, communal hegemony

Claudio GaribaY: Centro de Estudios Antropológicos, El Colegio de Michoacán, Zamora, Michoacán, México. claudio@colmich.edu.mx 


\section{INTRODUCCIÓN}

$\mathrm{E}$ n las dos últimas décadas del siglo XX en ciertos lugares de diferentes regiones rurales de México se ha desarrollado un singular tipo de comunalismo social sostenido por la explotación industrial de bosques comunales. El fenómeno parece involucrar tanto a comunidades de ascendiente cultural indígena como a comunidades campesinas de tradición mestiza. Este singular comunalismo parece combinar formas ancestrales de reciprocidad social con una moderna modalidad económica industrial, que en su desarrollo altera la organización social de origen y, en un complejo proceso político de "ingeniería social", reconstruye un nuevo orden social. Este tipo de organización social lo denomino comunidades forestales industriales $(\mathrm{CFI})^{1}$.

Las CFI combinan una serie de características que las distinguen: a) son sociedades de ascendiente campesino con culturas tradicionales específicas relacionadas con las formas de vida de las comunidades pequeñas; b) poseen en propiedad mancomunada amplios territorios y, en su interior, bosques que controlan como una sola unidad de explotación forestal; c) tienen además una empresa industrial de propiedad comunal que, desde una administración central, organiza la extracción y transformación del bosque en productos maderables y no maderables, que comercializan en las redes de mercado local, regional y global; d) desarrollan robustos sistemas locales de autogobierno con márgenes relativos de autonomía frente a poderes externos; e) elaboran una idea comunal de comunidad —ethos comunitario- que establece los valores y prácticas de su orden social.

\footnotetext{
${ }^{1}$ Especialistas del tema como Bray y Merino, 2004; Alatorre, 2000; Klooster, 1997, entre otros, se han referido al tema con diferentes nombres: "empresas forestales comunitarias", "comunidades forestales", “empresa social forestal". En general, los excelentes trabajos de esos autores han puesto un marcado acento en la empresa forestal comunitaria y sus impactos políticos, ambientales y sociales en la comunidad y la región. Aquí, con el término comunidades forestales industriales pretendo poner el acento en la comunidad en calidad de sujeto y en las características forestal e industrial como atributos de ese sujeto. La idea es dar primacía a la discusión sobre el orden social y político antes que a los temas referidos a la distensión organizacional.
}

A diferencia de la mayoría de las sociedades campesinas tradicionales caracterizadas por un patrón de relaciones sociales en el que la familia campesina es el centro organizador de la reproducción económica de la población local —con su economía organizada en torno al trabajo cooperativo del núcleo de parentesco y su lealtad a la familia-, en las CFI el eje organizador parece moverse hacia una economía industrial colectivista de alcance aldeano y hacia un orden social de carácter comunitariocorporativo.

En esa transformación comunalista, estas pequeñas sociedades parecen haber encontrado una alternativa diferente a la quiebra general de su economía campesina tradicional y al recurso emergente de la migración y una opción diferente frente al languidecimiento y disolución de su vida social. Por medio de una gran actividad de organización colectivista han controlado para sí el manejo de sus bosques; levantado una industria forestal y establecido un sistema económico marcadamente centralizado. Para lograrlo han reeditado versiones nuevas de corporativismo que recuerdan la eficacia defensiva de las antiguas "repúblicas de indios" de la época novohispana. Han impulsado versiones locales de ideologías comunalistas que exaltan la lealtad moral a un "nosotros", una que recuerda el afecto del creyente por su comunidad religiosa, y a la par han establecido prácticas de trabajo y organización propias de las empresas industriales modernas. De manera sustancial, estos comunalismos forestales han implantado un nuevo "orden social" que impone una dura disciplina a sus miembros a cambio de una oferta continuada de seguridad económica y certidumbre social en su vida cotidiana. Algunos ejemplos destacados de CFI son las comunidades de Ixtlán de Juárez y San Pedro el Alto, en el estado de Oaxaca; San Juan Nuevo, en Michoacán; El Balcón, en Guerrero; Pueblo Nuevo, en Durango o El Largo, en el estado de Chihuahua.

En general los estudios hechos en México sobre las CFI han dirigido su atención a la búsqueda de las claves organizacionales que hacen la diferencia entre un ámbito local que gobierna de manera sustentable sus recursos naturales y otros que están sumidos en ingobernables dinámicas de destrucción de sus bienes comunales. La preocupación de fondo ha sido la búsqueda de una salida a la 


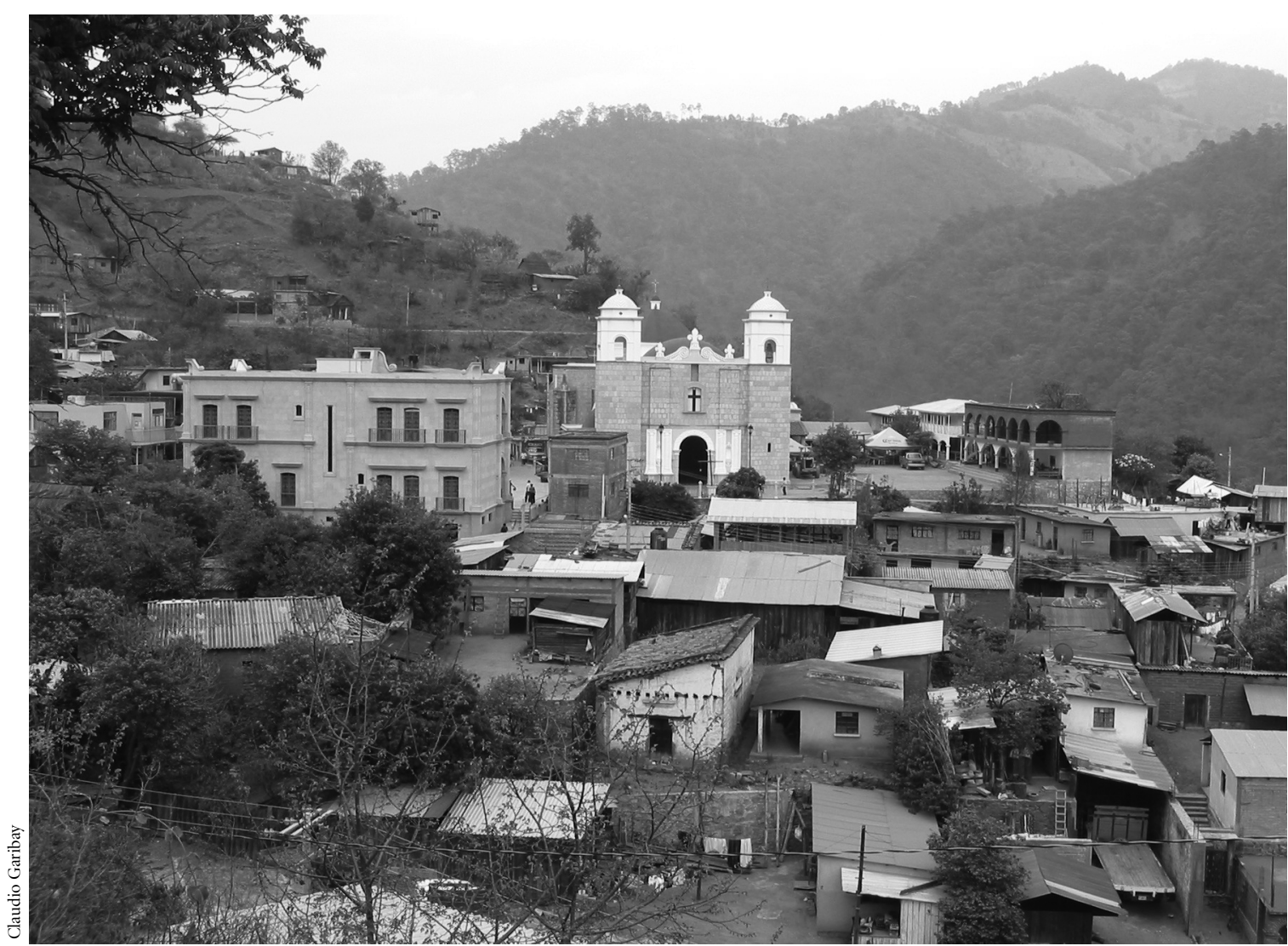

Vista del pueblo de San Pedro el Alto. Nótese el contraste entre espacios públicos ostentosos (iglesia y palacio de la agencia municipal) y las casas pobres.

paradoja de Hardin (1968) y su "tragedia de los comunes". Al efecto, el análisis se ha desarrollado en dos líneas generales: por un lado, el estudio del contraste entre el desempeño de comunidades forestales y los principios de diseños institucionales propuestos con base en los hallazgos del nuevo institucionalismo - y en especial en el argumento de Ostrom (1991), en su Governing the Commons-; por otro, la introducción del concepto de capital social - tal como lo propone Robert Putnam (1993), como modo de incorporar a la reflexión el tema de las prácticas culturales de reciprocidad social. En términos generales, la tesis de este enfoque es la siguiente: un diseño institucional adecuado y una acumulación suficiente de capital social que genere una socialización vigorosa y participativa de los individuos, permitirá que un ámbito comunitario pueda manejar de manera sustentable sus recursos de uso común, lograr una mayor equidad social, e incluso alcanzar una condición democrática.

Sin embargo, consideramos que ese fructífero debate ha dejado en la penumbra la reflexión de aspectos cruciales referidos tanto al tema del poder como al de la significación cultural. En este artículo nos proponemos reflexionar en esas dos temáticas que apuntan hacia objetivos un tanto distintos a los de la corriente general de estudios sobre ámbitos de comunidad. Por una parte, trataremos el problema de la hegemonía cultural en la construcción institucional del orden social en pequeñas sociedades campesinas; y por la otra, el problema del "régimen político" inherente al desempeño de las figuras de gobierno de los comunes. En este sentido, y a la luz de los 
casos ejemplares de las CFI, buscamos abrir el debate a partir de las siguientes interrogantes: ¿La permanencia social de las CFI en el contexto actual supone necesariamente la construcción de una comunidad moral encerrada en prácticas y valores sociales unitarios propios del orden social corporativo? ¿Las CFI, en tanto orden social constituido, tienen correspondencia directa con un régimen político autocrático, con uno democrático o con alguno de otro tipo?

\section{COMUNIDAD FRAGMENTADA Y COMUNIDAD CORPORADA}

Nuestro primer argumento postula que las CFI son resultado de un radical proceso de transformación estructural de la comunidad campesina tradicional. Un proceso que se inicia a partir de una condición de comunidad fragmentada y culmina en una comunidad corporada. A fin de explicar este argumento, estoy obligado a definir esas dos condiciones y la naturaleza de la transformación referida.

Inicialmente podemos pensar que las aldeas campesinas mexicanas forman un conglomerado de familias que, al menos por asentamiento residencial, guardan una condición de vecindad, ya sea en el caso de un asentamiento concentrado o de uno disperso. En esas aldeas dispuestas en el paisaje, cada núcleo familiar estará organizado a un mismo tiempo en tres aspectos: 1) como unidad de parentesco, en la que los miembros de la familia le deben lealtad primordial al grupo filial conforme a los términos singulares de su cultura; 2) como unidad económica de producción y consumo, que con el trabajo colectivo del grupo de parentesco procura la sobrevivencia del grupo familiar mediante un repertorio de estrategias económicas, y 3) como unidad política, atenta en influir en los espacios de poder y estructuras de dominación más amplios, con el propósito de garantizar la seguridad de sus miembros y la propiedad material del grupo; los derechos de acceso, posesión y uso alcanzados sobre tierras y recursos; la legitimidad de las posiciones, prebendas e intereses ganados o codiciados; y la cooperación y reciprocidad entre los vecinos respecto a objetivos y ad- versidades que sobrepasan los límites del núcleo familiar. La familia campesina, por lo común, es un grupo de lealtad muy sólido, poseedor de múltiples estrategias. En contextos campesinos el individualismo suele estar acotado por las obligaciones familiares, de modo que cuando los individuos hacen política en la aldea campesina, la hacen típicamente en representación del grupo familiar.

Los temas que con más frecuencia despiertan la pasión política de las familias campesinas son: la definición de derechos de acceso - particulares y colectivos-a tierras y recursos; la administración de los ámbitos comunales; la provisión de bienes y servicios colectivos; la resolución de pleitos y conflictos; y la representación de los intereses familiares en el ámbito comunal y frente al Estado y otros poderes externos. Pero también les apasionan los asuntos referidos a las alianzas familiares en sus múltiples sentidos, ya se trate de alianzas matrimoniales y de los parentescos rituales, de las prácticas de reciprocidad interfamiliar o de la participación en rituales sociales de afirmación identitaria y, de manera especialmente intensa, les exaltan los debates sobre el comportamiento moral de los vecinos. Un ejercicio nada inocuo, pues es a partir de la definición de lo bueno y correcto frente a lo malo e incorrecto que se organiza la sanción y la exclusión social.

A las aldeas campesinas también las podemos pensar como un espacio social equilibrado entre familia y comunidad: entre los alcances de los atributos y derechos ganados y ejercidos por la unidad doméstica como espacio nuclear de organización social y la intensidad de adscripción de los grupos familiares al agregado mayor de la aldea campesina. Se trata de un equilibrio que variará de caso en caso. Mientras más laxos sean los vínculos entre las familias campesinas más débil será la densidad comunitaria y viceversa.

Una formación social poco densa corresponde, por lo general, a sociedades campesinas organizadas en granjas familiares dispersas, autosuficientes en tierra, recursos y tecnología, de propiedad privada garantizada y con pocos bienes de uso común. En México es el caso típico de las sociedades rancheras del centro-norte del país con cultura individualista y competitiva. Estas formaciones sociales desplegarán su vida económica y social en una red vecinal de reciprocidades menos densa que aquellas 
en las que las granjas familiares comparten como bien común recursos estratégicos - por ejemplo, un sistema local de irrigación, un bosque mancomunado o incluso un peligro recurrente. En esta segunda situación el interés de las familias las vinculará en torno a la necesidad de regular el acceso al recurso compartido o en torno a la defensa conjunta de sus intereses ante fuerzas externas naturales o sociales ${ }^{2}$. Este segundo tipo de formación social será menos densa que una tercera configuración social campesina en la que las familias están agregadas en comunidades territoriales en las que la totalidad de la tierra y los recursos son de propiedad comunal y en las que el derecho de acceso al usufructo particular y colectivo de fracciones de recursos está mediado por el criterio de pertenencia a "la comunidad".

En este equilibrio entre familia y aldea, los numerosos casos de aldeas campesinas mexicanas se pueden ordenar conforme a una escala analítica, en la que el punto cero será una adscripción nula de las familias campesinas a la entidad comunitaria, de tal modo que "la comunidad no existe”; y el punto 100 será una interacción social, a tal grado densa y abarcadora de los ámbitos de la vida social, que individuos y familias se encontrarán integrados sistémicamente en la entidad superordenadora de la comunidad aldeana. Nos encontraríamos ante una situación en la que ir más allá supone para la comunidad campesina - con sus distinciones estructurantes de lo público y lo privado, lo familiar y lo comunal, lo individual y lo colectivo - desaparecer como tal, para convertirse en una especie de "comuna social", como una de aquellas rarezas sociales que eventualmente surgen en la historia a raíz de movimientos políticos o religiosos.

\footnotetext{
2 Los casos ejemplares citados por Ostrom (1991) en Governing the Commons corresponden típicamente a esta segunda situación. En esos ejemplos se presentan individuos (o grupos) formalmente independientes que comparten un recurso en bien común que los vincula y que tienen abiertas las opciones de cooperar o no cooperar, conforme a lo cual construyen su sistema institucional de elecciones. En un régimen de comunidad corporada, el modelo de elecciones expuesto por Ostrom se alterará radicalmente, pues el individuo tiene negada la opción de "no cooperar" conforme a su cálculo personal (o grupal) de costo-beneficio, precisamente porque no es un individuo (o grupo) formalmente independiente. $\mathrm{O}$ en otras palabras, porque la opción de no cooperar siempre es altamente costosa.
}

Pero la diferencia de densidad comunitaria no sólo es de escala sino también de "naturaleza". En un determinado umbral de gradación se presentará una mutación de los principios estructurantes del orden social aldeano; un punto de inflexión en el que la sociedad campesina fragmentada dejará de serlo para transformarse en una sociedad campesina corporada y viceversa. En nuestra opinión, el momento que marca el predominio de la naturaleza corporada en el orden social campesino es aquel en el que se cumplen las dos siguientes condiciones: 1) los compromisos cooperativos de los individuos y familias para con la entidad comunitaria dejan de ser voluntarios y se convierten en obligatorios, y 2) la renuncia a la acción colectiva comunal acarrea al individuo o al grupo doméstico la amenaza efectiva no sólo de exclusión del acceso a los recursos de uso común, sino también la amenaza de la expulsión social.

Así, se presenta una condición de sociedad campesina corporada en la que el sistema de autoridad es lo suficientemente fuerte y abarcador como para subsumir el interés individual y familiar al interés de la entidad comunitaria. La aldea campesina se representa a sí misma como comunidad territorial y mantiene para sí la facultad de asignación de tierras y recursos conforme a un régimen autónomo de derechos. Se presenta, así, unificada por un ethos convergente religioso, moral y político, que debe asegurar la lealtad primordial de los individuos a la comunidad por sobre otros ámbitos de adscripción social, ya sean la familia, la etnia, la nación, una religión, un partido político o cualquier otro. La entidad comunitaria monopoliza en su estructura institucional la representación social y política de los individuos y las familias frente a los poderes externos a la comunidad.

Si bien en términos analíticos hemos distinguido estos dos "tipos ideales" de sociedad campesina — sociedad campesina fragmentada y sociedad campesina corporadaes conveniente señalar que la realidad de las pequeñas comunidades campesinas es siempre una combinación compleja y sujeta a transformación. En verdad cada comunidad campesina presentará un determinado arreglo entre los alcances del compromiso obligado de la familia para con el espacio comunitario y los alcances del ámbito comunitario sobre los ámbitos de la vida social de 


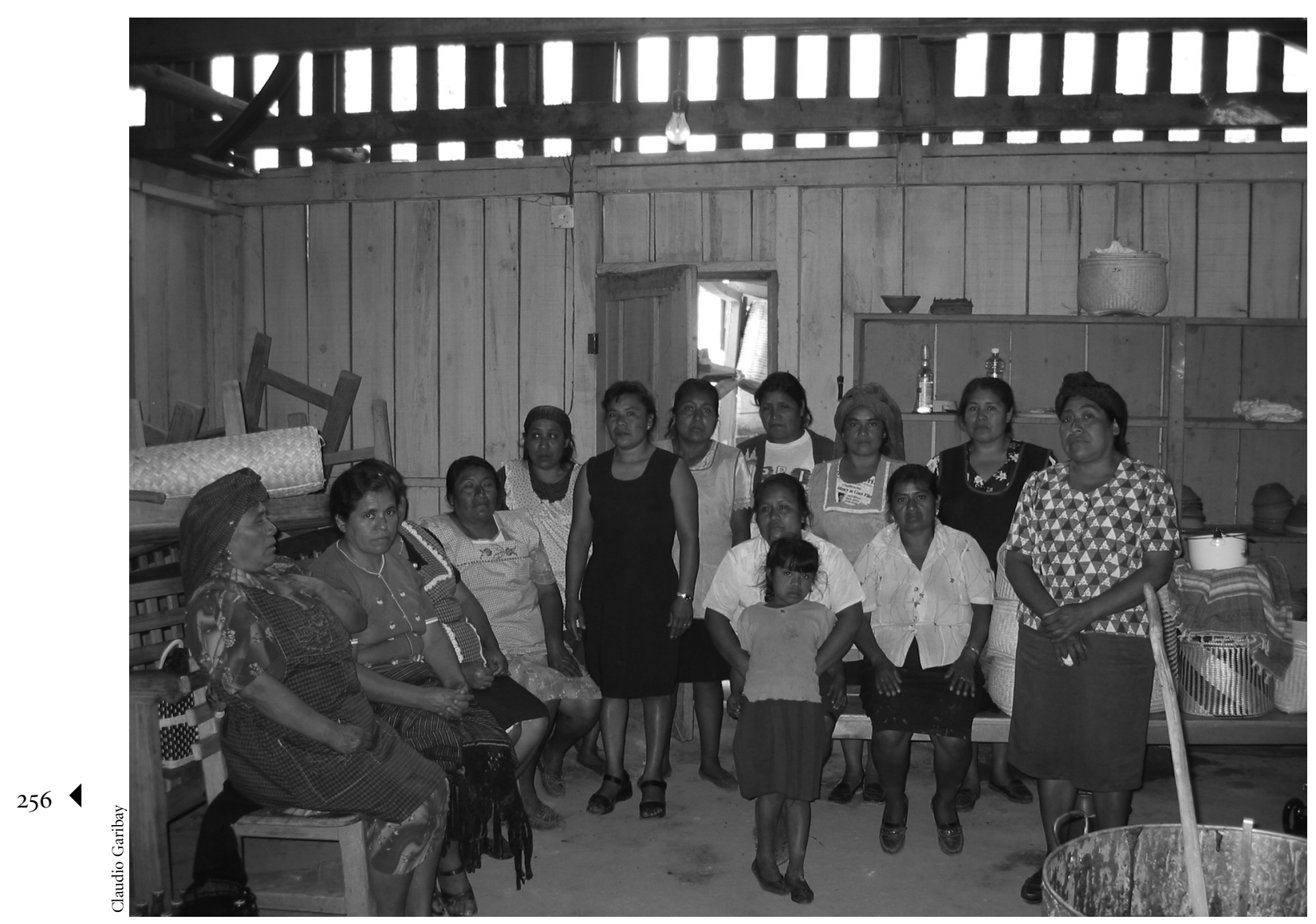

Mujeres que están haciendo su tequio en la cocina comunal, usada para las muchas fiestas cívicas y religiosas del pueblo.

los individuos de las familias campesinas. Pero aún más importante, la construcción del campo político comunitario estará, en principio, tensada por la normalización del significado de la idea compartida de comunidad. En ese sentido, en el trasfondo de cada decisión aldeana se estará disputando la dirección de la idea imaginada de comunidad, ya sea hacia la de una comunidad fragmentada o a la de una comunidad corporada.

\section{EL COMUNALISMO FORESTAL}

El origen de estas CFI es conocido y documentado. Hacia finales de la década de 1970 surgieron múltiples movimientos sociales en algunas regiones forestales del país en protesta contra el régimen de concesiones forestales prevaleciente desde la década de 1940. Éste le daba a la empresa concesionaria privada o gubernamental el control total de los bosques comunales para su explotación exclusiva por periodos de veinte o más años, a cambio de una renta pagada, a nombre de la comunidad propietaria, en un fondo de ahorro forzoso bajo control gubernamental; y negaba a la comunidad propietaria el derecho efectivo de repudiar a la empresa concesionaria y usufructuar el bosque para sín.

\footnotetext{
${ }^{3}$ Varios trabajos han documentado la historia de los comunitarismos forestales. Entre ellos destaca el trabajo de Bray y Merino, 2004 Un interesante trabajo referido al caso de Oaxaca es el desarrollado por Aseteco, 2002.
} 
El resultado de esas movilizaciones sociales, en un contexto nacional de crisis del modelo económico populista y de cierta apertura política bajo las presidencias de José López Portillo y Miguel de la Madrid, culminó durante la década de 1980 en la quiebra del régimen de concesiones forestales, en modificaciones al texto de la ley forestal en favor del aprovechamiento comunitario, y en el impulso de una política gubernamental —un tanto errática- de creación de empresas forestales comunales. En esos años el papel de la prensa nacional —especialmente la revista Proceso y el periódico Uno más Uno- fue relevante para dar voz a las quejas campesinas e impulsar sus movilizaciones sociales. También fue importante la intervención política a favor de los campesinos de un pequeño, pero activo e inteligente, bloque de funcionarios públicos ubicados en la "izquierda" del partido oficial, —o bien provenientes de la izquierda radical de la década de 1970 - y colocados en puestos claves del aparato gubernamental encargado del control forestal ${ }^{4}$.

Ese bloque de funcionarios comprometidos en su activismo social - y de una y otra forma vinculado con liderazgos campesinos en comunidades - se dio a la tarea de elaborar el discurso político del comunalismo forestal y se afanó en su realización. Era un discurso perteneciente, de alguna manera, a aquella larga tradición comunalista mexicana, heredera del ejido colectivo posrevolucionario del periodo cardenista en la década de 1930, que exaltaba el valor superior de la vida en comunidad y que en su visión modernizadora se combinaba con un productivismo cooperativista y socialista. Se trataba de un proyecto que reivindicaba la capacidad y el derecho del campesinado, desde una organización colectiva, de manejar por sí mismo y para sí sus recursos forestales, superar la pobreza e impulsar un desarrollo social equi-

\footnotetext{
${ }^{4}$ La cabeza visible de ese bloque era el ingeniero Cuauhtémoc Cárdenas, en aquellos años subsecretario forestal y gobernador del estado de Michoacán. En el contexto de la sucesión presidencial de 1988, decidida por el presidente De la Madrid a favor de los "tecnócratas" y del licenciado Salinas de Gortari, ese bloque de la izquierda oficial se separa del régimen y del oficialista Partido Revolucionario Institucional (PRI) y se propone la disputa por la presidencia de la República. En el proceso incorpora a una parte de la izquierda radical y universitaria en lo que posteriormente sería el Partido de la Revolución Democrática (PRD). En Aseteco (2000) se encuentra un interesante perfil de las ideas y prácticas de este grupo de funcionarios para el caso del estado de Oaxaca.
}

tativo (si no es que igualitario). A las prácticas depredadoras de las grandes compañías, este discurso oponía el valor ético de la "explotación racional", hoy reciclado en el discurso del "desarrollo sustentable", al mismo tiempo que asignaba a la empresa forestal comunitaria el papel de motor económico de una renovada utopía social comunitaria fundada en la explotación industrial colectiva de los bosques.

En la mayoría de los casos conocidos que sucedieron en la década de 1980, la iniciativa de creación de empresas forestales comunitarias partió de las agencias gubernamentales, y en algunos otros de liderazgos surgidos en el interior de las comunidades. En ambas situaciones, los extensionistas del bloque izquierdista gubernamental se vincularon con líderes comunales, y cada cual desde su posición se dio a la tarea de construir una agenda conjunta de intervención en el orden social y político existente en la comunidad en cuestión. Los promotores campesinos se enfocaron en la construcción de los consensos internos para lograr la nueva hegemonía comunal; y los funcionarios, en facilitar el desempeño del proyecto colectivista en términos legales, técnicos y políticos. Los emergentes liderazgos campesinos tenían el afán del dominio político de su comunidad, mientras que los funcionarios, a través de la intermediación política en las comunidades, pretendían la construcción de coaliciones regionales campesinas y el fortalecimiento de su posición política nacional. La lucha contra las concesiones forestales estuvo marcada por la organización de coaliciones regionales de comunidades llamadas uniones. Estas organizaciones se convirtieron en el espacio privilegiado de intermediación política a favor del comunalismo forestal que vinculaba en un mismo proyecto político a funcionarios, asesores, líderes de organizaciones campesinas y autoridades comunales.

Para el común de los habitantes campesinos la ilusión social puesta en esas empresas comunales era sencilla: se trataba de generar una alternativa económica que ofreciera empleo remunerado a la población local, y obtener de la explotación del bosque mancomunado ganancias para las necesidades públicas de la comunidad. La organización requerida parecía simple. En virtud de que los bosques eran de propiedad común, la empresa sería co- 
lectiva y el dueño jurídico el mismo núcleo agrario. Por consiguiente, la organización de la empresa quedaría al mando de los órganos de gobierno interno de la entidad agraria, es decir, según la ley, de la "asamblea general" en su papel de autoridad máxima del núcleo agrario y del "comisariado" — comunal o ejidal—en su papel de órgano interno de gobierno sobre el territorio comunitario. $Y$ a fin de dar facilidades a la empresa para realizar contratos, gestiones, representaciones y transacciones conforme a las exigencias jurídicas, aquélla se formalizaría en "persona moral" de carácter mercantil y adoptaría la figura jurídica de "unidad económica especializada de aprovechamiento forestal comunal". Una figura jurídica ex profeso creada e inducida por la burocracia agraria del gobierno federal en los ejidos y comunidades forestales.

La organización comunal, que llena de ilusión funda su empresa forestal comunitaria, se topa con el imperativo cotidiano de coordinar y pagar a cientos de trabajadores, realizar múltiples trámites gubernamentales, presionar a prestadores de servicios, extraer, transportar y colocar importantes volúmenes de madera en el merca- do, controlar embarques, presionar a deudores, mantener a raya a los acreedores, resolver disputas laborales, administrar importantes volúmenes de dinero, presentar cuentas claras, decidir el destino de las utilidades y, a pesar de los imponderables, mantener funcionando el complejo industrial. Igualmente se percata de que la viabilidad de su empresa depende de la adopción de sistemas organizacionales de la empresa mercantil; es decir, de una organización estructuralmente autocrática y disciplinaria orientada a la búsqueda de utilidades en entornos de competencia mercantil. Pero más allá de un plano meramente organizacional, se da cuenta de que la exigencia operativa de la empresa forestal comunal deriva en una fuerte concentración de poder, que induce a cambios sustanciales en los arreglos institucionales y culturales del orden social de la comunidad local. Y como en la fábula del aprendiz de brujo, aquella criatura animada por la sencilla finalidad de dar empleo al campesino y beneficios al poblado adquiere vida propia, crece y arrastra a la comunidad local a realidades nuevas y senderos imprevistos. Arrastra a la comunidad campesina a su inesperada transformación social.

\section{LA EXIGENCIA DE LA EMPRESA FORESTAL COMUNAL}

Como es sabido, cualquier organismo empresarial orientado por fines crematísticos tiene por imperativo el retorno incrementado del capital inicialmente invertido. El margen de utilidades depende de la relación de "eficiencia” entre el capital invertido y el retornado. La viabilidad de una empresa a largo plazo sólo es posible si, dentro de escenarios económicos y políticos competitivos y cambiantes, la relación costo-beneficio se mantiene de manera consistente en signos positivos. Ello supone la construcción de una empresa cuya organización y gestión de los factores de producción (trabajo, capital, recursos) sea flexible, adaptable, informada, competitiva, de tal modo que le permita aprovechar para sí los "costos de oportunidad" que se le abren en el mercado. Pero también supone una empresa con un control riguroso de su propia organización; un control operacionalmente autoritario. Este principio general de eficiencia empresarial aplicado al caso singular de las empresas industriales forestales obliga a las organizaciones empresariales comunales a la adopción —quiéranlo o no—- de los siguientes imperativos de eficiencia:

Control territorial centralizado. Dada la natural disposición extensiva del bosque en el territorio y la lenta tasa de incremento anual de los volúmenes de madera por unidad de área, la eficiencia de la empresa forestal comunitaria dependerá del control territorial centralizado y planificado de amplios predios boscosos durante largos periodos de tiempo (decenas de años). El control territorial le es imperativo para garantizar el desarrollo de infraestructura —caminos, torres vigía, campamentos, etc.- con fuertes inversiones iniciales de lenta tasa de recuperación; pero también por las exigencias técnicas y legales a favor de un manejo controlado del bosque conforme a criterios silvícolas de conservación y sanidad. En efecto, la empresa forestal es responsable ante la ley -en virtud de que los bosques son constitucionalmente de "interés público" - de garantizar la permanencia del bosque en adecuadas condiciones ambientales a lo largo del tiempo y, por tanto, de proveer lo necesario para man- 
tenerlo en buena salud, evitar incendios, restaurar áreas degradadas, sanear áreas plagadas, proteger la flora y fauna locales, evitar aprovechamientos fuera de programa, entre otras muchas exigencias. El incumplimiento de ello puede derivar tanto en apreciables pérdidas económicas como en la cancelación de los permisos gubernamentales de aprovechamiento. De tal manera que la empresa se ve obligada a imponer la disciplina interna, organizar dispositivos para defender el territorio forestal de saqueos externos e imponer a los propios habitantes de la comunidad la exclusión de todo aprovechamiento particular que no esté adscrito a las normas establecidas por la planificación central del "plan de manejo forestal".

La empresa forestal comunal, en su imperativo de control territorial centralizado, frecuentemente se enfrenta a conflictos agrarios no sólo con propietarios y comunidades vecinas, sino también al interior de sí misma, con aquellos que por una u otra razón reivindican porciones de terreno en propiedad particular o bien en posesión de una facción comunitaria. En estas dinámicas políticas se pone en juego no sólo la propiedad de una determinada porción del bosque, sino también la determinación de a quién pertenece y a quién se excluye de la comunidad. Este mismo imperativo territorial también puede generar conflictos referidos a los derechos de acceso de las familias y los individuos a los recursos del bosque. En este punto la hegemonía de la comunidad como totalidad sobre sus miembros o la preeminencia de los individuos y grupos por sobre el conjunto comunitario entran en tensión política. Así pues, el tema del control central del territorio en oposición a un acceso abierto o poco regulado a la tierra y los recursos, frecuentemente provoca profundas divergencias al interior de la comunidad entre el interés de la empresa comunal y el interés de personas, familias, grupos y facciones al interior de la comunidad. En algunos casos se hace posible conciliar las divergencias mediante acuerdos estables, en otros lo que prevalece es la fuerza y el boicot. En ambas situaciones el control territorial centralizado supone la modificación de los acuerdos institucionales tradicionales del orden comunitario.

Control jerárquico. Dada la necesidad de coordinar una amplia variedad de actividades concatenadas que re- quieren de la concurrencia de un personal numeroso y especializado en el marco de tiempos y costos predeterminados, la eficiencia empresarial dependerá de un control jerárquico organizado conforme a claras líneas de mando laboral El control jerárquico es el único modo eficiente de organizar las empresas industriales forestales en virtud de la escala y complejidad de sus operaciones.

El ejercicio del control jerárquico en la empresa comunitaria abre un abanico de problemas en el orden social comunitario. Por ejemplo: los conflictos derivados de la no correspondencia entre la jerarquía organizacional de la empresa y la jerarquía social-cultural de la comunidad local. Mientras que el criterio para la ocupación de los puestos en la empresa debe ser —en términos de eficiencia- la habilidad como trabajador, el criterio cultural de jerarquía social comúnmente responde a otros valores de distinción social, como el prestigio, el linaje o la riqueza. De esta manera se da el caso en que la empresa ocupa personas con mayor prestigio social en posiciones subordinadas a individuos socialmente inferiores, lo que redunda en el debilitamiento político de la empresa frente a la comunidad. O bien lo contrario, individuos sin habilidades gerenciales que ocupan puestos directivos en razón de un puro compromiso político con el régimen de distinción social, lo que redunda en el debilitamiento organizacional y económico de la empresa.

Pueden observarse situaciones de tensión provocadas por la exigencia de una disciplina productiva rigurosa y controlada propia de los procesos industriales frente a los hábitos lentos y relajados asociados a una cultura campesina tradicional. O el cuestionamiento de autoridad y jerarquía derivada de la condición doble del comunero como trabajador y socio. En efecto, en el ejercicio cotidiano de la cadena de mando los linderos entre autoridad y autoritarismo de los mandos, y la aceptación y resistencia de los que obedecen siempre son tenues y renegociados; pero a diferencia de la empresa forestal privada, en la que la legitimidad del mando es incuestionable y en la que el conflicto se enmarca en los códigos de la relación obrero-patronal, en la empresa forestal comunitaria los trabajadores pueden cuestionar el control jerárquico aduciendo su condición de "copropietario" 


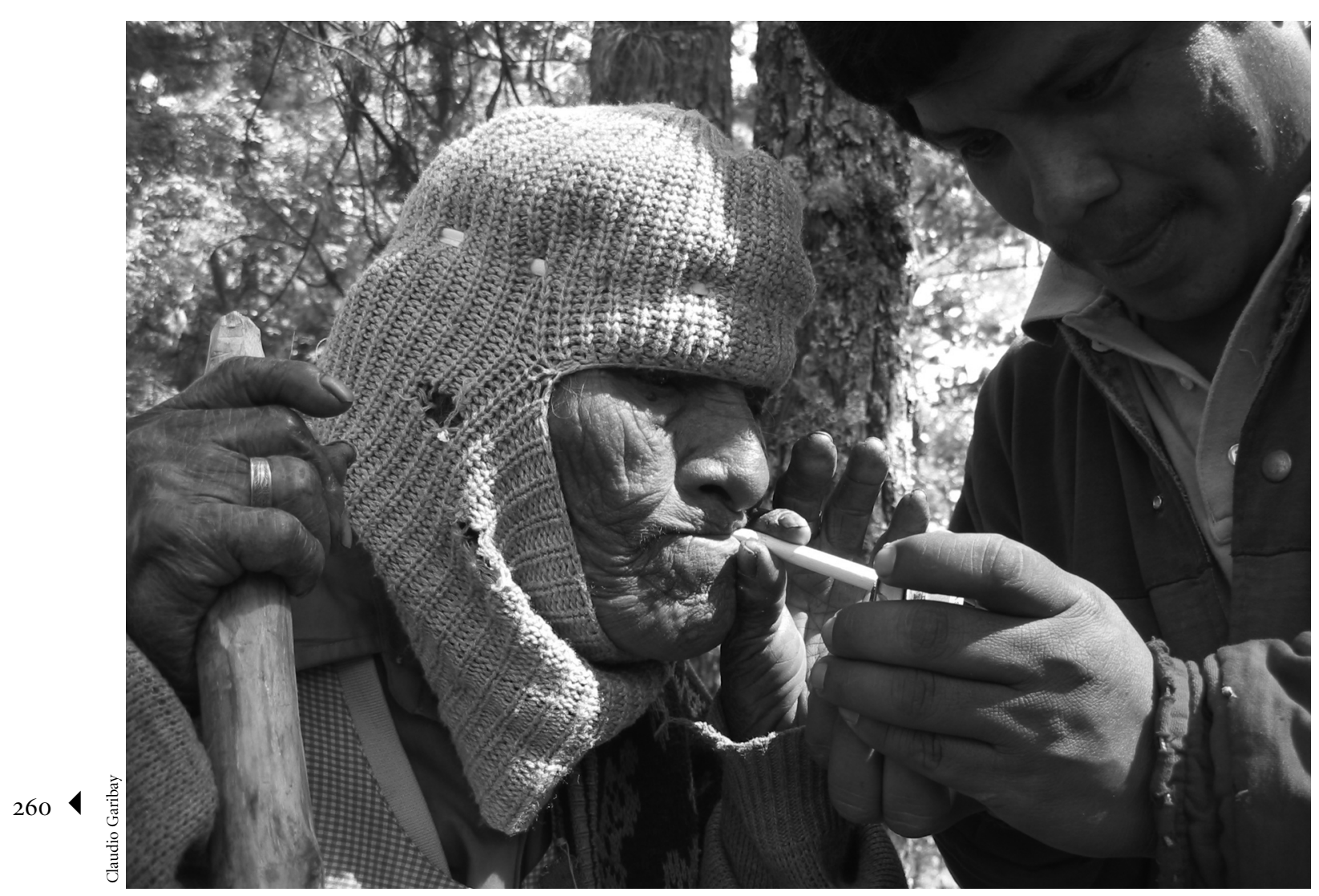

Anciana en la celebración a los chanekes, espíritus del bosque.

de la empresa y, por tanto, derivar una tensión laboral en un conflicto político comunitario.

Control autocrático. Dado que la empresa forestal —al igual que cualquier otra- realiza su retorno de capital bajo márgenes siempre variables de incertidumbre, $\mathrm{y}$ que el cálculo de las estrategias de inversión requiere de habilidades para discernir los "costos de oportunidad" a corto, mediano y largo plazo, la eficiencia empresarial dependerá del control autocrático sobre la empresa por parte de su grupo directivo, de tal manera que se permita una toma de decisiones en forma ágil, inapelable y definitoria en circunstancias cambiantes, tales como recortes de personal, despidos disciplinarios, reubicación de puestos, modificaciones tecnológicas, reorientaciones productivas, etc. Si bien un conjunto diverso de leyes de carácter laboral y mercantil de alguna manera limita la arbitrariedad total, es evidente que el manejo empresarial eficiente tiene que ver más con un concentrado ejercicio de poder desnudo y menos con la construcción de consensos.

El tema del control autocrático de la empresa se convierte en el dilema central de la política comunitaria. En especial si la empresa se consolida y aumenta su peso relativo en la economía y vida social de la comunidad. Por su posición estratégica el grupo directivo concentrará tanto poder que fácilmente podría ser dirigido en beneficio propio. El control de fondos financieros, contrataciones, contactos comerciales y políticos, información puntual sobre debilidades y fortalezas de la empresa, y de los demás aspectos derivados de la posición privilegiada consustancial al puesto directivo, puede derivar con 
facilidad — hablando como Pierre Clastres (1987) — en la "inversión de sentido de la deuda". Un "contraflujo" de reciprocidades es de tal modo invertido que ya no será el grupo directivo quien debe su posición privilegiada a la asamblea comunal, sino al contrario, cada uno de los miembros del pleno comunal quienes deberán al grupo directivo sus empleos, posiciones y prebendas.

Esta "sintaxis" organizacional de la empresa forestal fundada en los principios del control territorial, jerárquico y autocrático puede, fácilmente, extenderse a la totalidad de la organización social de la comunidad. La empresa, de ser pensada como un negocio periférico y adicional a la economía familiar, se desplaza al centro de la vida social y se convierte en un poderoso organismo que empuja a la reconfiguración de las coordenadas económicas, sociales y políticas de la aldea campesina. Como podrá suponerse, todo esto abre un complejo escenario político de disputa e incertidumbre.

\section{HEGEMONÍA COMUNAL}

Con frecuencia se olvida que las pequeñas sociedades campesinas no son idílicos mundos homogéneos, armoniosos e igualitarios. Las sociedades campesinas son, más bien, espacios cruzados por divisiones de género, generación, linaje, etnia, riqueza o clase; jerarquizados conforme a sus singulares principios culturales de distinción y prestigio social, y por lo común, sujetos a tensiones y conflictos que pueden llegar a ser muy agudos. Pero también son espacios donde individuos y grupos, desde sus diferencias y distinciones, suelen estar comprometidos, en mayor o menor medida, con prácticas de acción colectiva que necesitan de complejos consensos - no siempre evidentes - en torno a un significado compartido de lo que es y debe ser el orden social en que viven.

En tal sentido, lo que hace de una aldea campesina una "comunidad" más que un conjunto de arreglos institucionales, más que un grupo con valores y comprensión común, es el estar comprometidos en el mismo argumento, enganchados en el mismo razonamiento, la misma red, el mismo discurso. Así, las estrategias alternativas, los desacuerdos, los conflictos de metas y valores son disputados, negociados y renegociados conforme a las pautas y alcances del mismo discurso; de acuerdo con esa red de compromisos que nosotros llamamos ethos comunitario.

Desde este punto de vista las convenciones sociales que fundamentan un determinado ethos comunitario no debieran entenderse sólo en el sentido estrecho de un sistema de reglas reguladoras del comportamiento de individuos y grupos, organizadas en relación con un determinado arreglo institucional, a la manera en que en una computadora un software "gobierna" a un hardware, sino más bien como un repertorio, relativamente ambiguo y no sistémico, de convenciones que son gobernadas por un discurso hegemónico moldeado en la cotidiana definición tanto del significado legítimo de lo que es y debe ser "la comunidad", como del alcance del compromiso moral de los individuos y grupos para con ella 5 .

Sin embargo, la hegemonía de un determinado ethos comunitario no es algo dado de una vez y para siempre, sino algo creado por un proceso político concreto. En tal sentido, el proceso hegemónico será una secuencia de eventos a través de los cuales se legitima, redefine y disputa el poder y el significado en todos los ámbitos del orden social. Por medio del proceso hegemónico se logra transigir entre los grupos en disputa un proyecto social y moral en común por sobre las diferenciaciones de posición, rango o clase dentro de la comunidad.

Eventualmente el proceso hegemónico culminará con un bloque político en el poder que logra dominar, por medio de una combinación de coerción y consentimiento, tanto el discurso comunitario - poder en significación-, imponiendo una "versión oficial" de lo que es y debe ser la comunidad, como la organización comunitaria — poder en organización-, capturando para sí el

\footnotetext{
${ }^{5}$ Los conceptos de comunidad y ethos comunitario son ideas trabajadas por muchos autores. En este caso hemos partido de un destilado de ideas de muchos autores, en el cual el peso de algunos fue más importante: para comunidad y ethos comunitario, Sabean (1984) y Sartori (1988); para el concepto de hegemonía comunal, Mallon (2003); para niveles de consenso y, de alguna manera, la distinción entre regímenes políticos, Sartori (1988); y finalmente, para la comprensión del tema del poder en significación y en organización, la deuda es con Eric Wolf (2001).
} 
control de las posiciones institucionales de la comunidad y remodelándolas conforme al nuevo discurso comunal.

Ahora bien, en esta reflexión vale la pena distinguir tres posibles niveles en torno a los cuales las comunidades campesinas construyen los consensos que organizan su orden social: 1) consenso al nivel de constitución comunitaria, es decir, aquellos consensos de orden cultural que refieren a los valores morales constitutivos del sistema básico de creencias de la comunidad; 2) consensos a nivel de régimen comunitario, que refiere a los acuerdos organizacionales acerca de las reglas del juego en la comunidad y su construcción institucional, y 3 ) consensos a nivel de práctica política comunitaria, relacionados con los modos político-administrativos conforme a los cuales se procesan los problemas específicos.

Como podremos suponer, la ruptura del consenso a escala constitucional generará conflictos muy agudos, $y$ frecuentemente mortales, en virtud de que afecta las creencias más preciadas de la comunidad. Por ejemplo, la supresión del sistema de castas en una sociedad de castas; la diversidad religiosa en una cultura de unicidad religiosa; la privatización del bien comunal en una cultura comunalista; la comunalización de la propiedad privada en una cultura de rancheros; la igualdad étnica en una cultura racista.

La ruptura de consenso a nivel de régimen comunal es más fácil de restaurar que una ruptura constitucional. Mientras las creencias fundamentales de la comunidad moral no sean amenazadas es posible rediseñar el modelo organizacional del gobierno comunal. De alguna manera, el argumento de Ostrom (1991) privilegia este segundo nivel del orden social. En él la eficacia del modelo organizacional de gobierno de los bienes comunes variará conforme con la forma singular en que los arreglos institucionales se conjugan de acuerdo con su propuesta de los "ocho principios de diseño" característicos de instituciones robustas 6 . Pero el consenso a nivel de

\footnotetext{
${ }^{6}$ Los principios de manejo encontrados por Elinor Ostrom son: 1) límites claramente definidos; 2) coherencia entre reglas de apropiación y provisión de condiciones locales; 3 ) arreglos de elección colectiva; 4) supervisión; 5) sanciones graduadas; 6) mecanismos de resolución de conflictos; 7) reconocimiento mínimo de derechos de organización; y 8) entidades anidadas (Ostrom, 1991). Quizá un principio a agregar
}

régimen comunal no sólo incumbe a los consensos organizativos sobre la estructura de gobierno y su funcionamiento, sino también a los consensos sobre la organización del régimen político, es decir, acerca de la forma cómo se significa, legitima, accede y ejerce el poder en el ámbito comunal.

En apego a la teoría política clásica pensamos que existen cuatro regímenes políticos posibles en ámbitos comunitarios: 1) autocracia comunal (caciquismo), caracterizada por el dominio de un pequeño grupo legitimado por su poder personal; 2) régimen de notables, caracterizado por el dominio de un pequeño grupo legitimado por un sistema institucional tradicional de posiciones de prestigio; 3) régimen de democracia directa, caracterizado por el dominio de un sistema de asamblea comunal en deliberación directa y la toma de decisiones por el principio de mayoría, apoyado en el respeto a la garantía de la minoría de que eventualmente pueda convertirse en mayoría; y 4) régimen de democracia indirecta, caracterizado por la elección de representantes, encargados de constituirse en asamblea y de deliberar, negociar y alcanzar acuerdos dentro de los principios ya dichos de mayoría y garantía a la minoría.

Finalmente, la ruptura de los consensos en el tercer plano, en el nivel de la política comunitaria, es con frecuencia relativamente fácil de restaurar, siempre y cuando exista legitimidad en los dos primeros niveles. Éste es el ámbito del consenso en el tratamiento de los asuntos cotidianos, de los modos en que se ejerce y debe ejercerse la autoridad, y de la elección de las estrategias por implementar respecto a asuntos operativos de toda índole. Es el espacio privilegiado de la deliberación, ya sea en asamblea, ya al interior del bloque dominante. Por supuesto, los tres niveles que hemos distinguido son de orden analítico; en la realidad, los procesos sociales se presentan como una totalidad, de tal modo que no es extraño que un determinado problema, que aparentemente se presenta en el ámbito de lo cotidiano, pueda expresar rupturas de orden de "régimen" o incluso de orden "constitucional".

sería el siguiente: 9) capacidad de negociar una significación cultural compartida. 


\section{LA EMPRESA FORESTAL COMUNAL Y EL CONFLICTO FACCIONAL}

En las aldeas campesinas, la fundación de empresas forestales comunitarias abre en el mismo acto de su creación un campo de fuerza tensado por el conflicto político entre dos proyectos hegemónicos de comunidad, entre dos ideas comunales de comunidad. De un lado un movimiento comunitarista, que desde la empresa forestal apunta hacia la realización de una idea organizacional corporativa de comunidad basada en vínculos obligatorios. Del otro, un contra movimiento familiar-particularista, que en actitud reactiva defiende una idea de comunidad de grado más liberal, a saber, la idea de comunidad entendida como una red de vínculos voluntarios entre vecinos establecidos con base en la independencia organizacional de la unidad doméstica. Pronto a los individuos y familias campesinas se les presenta un dilema ineludible: apoyar o resistirse. En estos términos, podemos ver a la comunidad local tensada por la confrontación y negociación entre una serie de principios estructurantes opuestos:

1. En el plano económico se da una ordenación socioeconómica organizada como una multiplicidad de unidades domésticas campesinas marcadamente autosuficientes, descentralizadas, particulares e independientes en su gestión territorial y productiva; frente a su opuesto, un modelo de empresa colectiva de gran escala y complejidad organizacional orientado al control centralizado de los recursos naturales y sociales.

2. En el plano de la interacción social se observa un orden social basado en márgenes relativamente amplios de independencia social "horizontal" de cada familia respecto a las demás de la aldea, y una cooperación relativamente voluntaria en las tareas colectivas y la organización aldeana, en oposición a un modelo de dependencia vertical de las familias respecto a la economía política de la empresa y una cooperación obligatoria para con el conjunto aldeano.

3. En el plano político-institucional se da un modelo de autoridad de baja densidad y capacidad de autogobierno, restringido a funciones de gendarmería, me- diación de disputas, organización cooperativa simple y representación débil de los intereses colectivos ante poderes externos. El modelo de autoridad opuesto es de alta densidad y capacidad de autogobierno y abarca funciones ordenadoras de la vida económica, cívica, ritual y moral de la aldea campesina.

4. En el plano de la significación social se nota una idea de comunidad que si bien exige cierta unicidad moral y ritual heredada de su tradición, se plantea como relativamente abierta a cierto grado de liberalidad social y lealtad limitada a la comunidad. En oposición, el otro modelo afirma un grado mayor de unicidad moral y exige una lealtad primordial hacia el conjunto aldeano. En los mismos términos podemos decir que se abre un conflicto de legitimidad entre dos principios de distinción y jerarquía social: la legitimación del principio basado en la habilidad y el conocimiento profesional en oposición a principios de jerarquía social tradicional basados en el prestigio ceremonial, en el abolengo de origen o en la riqueza familiar.

A la luz de los múltiples ejemplos observados desde finales de la década de 1970 en las comunidades forestales, la disputa entre estas dos ideas de comunidad ha derivado en procesos y resultados complejos. En general, a la vuelta de los años, y tras duras disputas internas, la mayoría de las experiencias forestales comunitarias fracasaron y cerraron sus operaciones. La mayoría terminó en el agotamiento de la iniciativa colectiva, con una aldea políticamente exhausta y con el regreso del experimento colectivista al modelo estructural anterior, aunque no necesariamente al equilibrio económico y político previo a la aventura. Las causas del fracaso aducidas por los protagonistas de esas experiencias han sido similares: disputas por el control de la dirección de la empresa; corrupción de los grupos directivos en perjuicio del común; enriquecimiento ilícito de una clientela cercana al grupo en control; inequidad en el reparto de beneficios; errores de administración y operación de la empresa; huelgas y bloqueos de facciones opuestas a la dirección, etc. En un plano más comprensivo, y más allá de los eventos singulares, las causas de estos fracasos comunitarios bien se pueden atribuir a la propia dificultad constructiva del 
modelo forestal industrial, a la resistencia política local ante la exigencia corporativa y a la resistencia al nuevo proyecto de comunidad moral.

En contraste, en aquellos raros casos en que el proyecto comunitarista ha triunfado - término siempre temporal y relativo - la localidad campesina ha entrado en una compleja dinámica de construcción de un orden social corporado. Es decir, en un movimiento de absorción de los diversos ámbitos institucionales de la vida social en una sola estructura organizacional (poder en organización), a la par que en un movimiento de construcción y exaltación de una idea comunitarista de comunidad (poder en significación). Es un proceso que apunta hacia la construcción de una entidad comunitaria que articula dentro de una sola estructura formal de organización un control territorial, una economía empresarial-colectiva, un sistema fuerte de autoridad colectiva, una unicidad moral y ceremonial, y un monopolio de intermediación política y social de los individuos de la comunidad ante los poderes externos. Un proceso de corporativización que en los casos más extremos avanza hacia una especie de "cierre social", hacia una intimidad comunitaria que logra integrar dentro de sí una suerte de pequeña totalidad social, en dirección a un "nosotros" comunitario orgánicamente articulado, a una comunidad moral. Con base en esta discusión analizaré el caso de San Pedro el Alto, en Oaxaca.

\section{SAN PEDRO EL ALTO, OAXACA}

La comunidad de San Pedro el Alto es un caso consumado de transformación corporativa. Un caso excepcional de comunalismo que por su extremidad bien puede tomarse como ejemplo paradigmático de corporativismo de las comunidades forestales industriales. En este caso la empresa forestal comunal, fundada en la década de 1980, se inserta de tal modo en la vida social de la comunidad que revierte todo proceso de privatización de las tierras comunales. La empresa centraliza el territorio y el con-

\footnotetext{
${ }^{7}$ Una discusión más extensa desde un punto de vista externo puede encontrarse en Garibay (2002); y desde un punto de vista de un actor privilegiado del proceso de San Pedro, en Aseteco (2002).
}

trol del bosque; absorbe la energía laboral de la comunidad; transforma la estática economía campesina familiar en una dinámica economía colectivista aldeana; y culmina con el establecimiento de un sistema económico comunitario bajo un modelo colectivista que eleva de manera importante los ingresos brutos de la comunidad.

El flujo de dinero derivado de la forestaría industrial fortalece la posición del gobierno comunal frente a su comunidad, y le permite no sólo una mayor influencia sobre la población, sino también, con el financiamiento de las necesidades materiales y de las prácticas rituales de la comunidad, el impulso de una reingeniería social a favor de la hegemonía de un nuevo orden comunal, marcadamente corporativo y tradicionalista. En San Pedro el Alto, de manera curiosa, la empresa forestal industrial - a pesar de su carga de modernidad - parece desempeñar en la población actual un papel similar al de las "cajas de comunidad" o las "cofradías de los santos" en la comunidad colonial. Es decir, el de una organización económica de carácter colectivo orientada a financiar las necesidades del pueblo en momentos de crisis, la construcción de obras comunales y, especialmente, el sostenimiento, con pompa y dignidad, de las celebraciones rituales de la comunidad.

San Pedro el Alto es una comunidad campesina de ascendiente indígena zapoteca, de 4000 habitantes, ubicada en la Sierra Sur del estado de Oaxaca, aproximadamente a $100 \mathrm{~km}$ de la capital del estado. La comunidad es propietaria de 30000 hectáreas de tierra, cubiertas en su mayoría por bosques templados de pino y encino, y de algunas áreas agrícolas proporcionalmente menores de roza y quema, de humedal y de pequeño riego. El régimen de propiedad es el de comunidad agraria, que en términos jurídicos define que el territorio comunal (predio comunal) es propiedad no de los individuos en lo particular, ni tampoco de la suma de individuos en condominio, sino en realidad de la entidad agraria indivisa. En tanto que persona moral frente a la ley agraria está representada por el comisariado de bienes comunales. En términos metajurídicos, San Pedro es una comunidad territorial de larga data histórica: una pequeña sociedad organizada por un cuerpo de prácticas culturales y un sistema de gobierno tradicional que se autogobierna y 


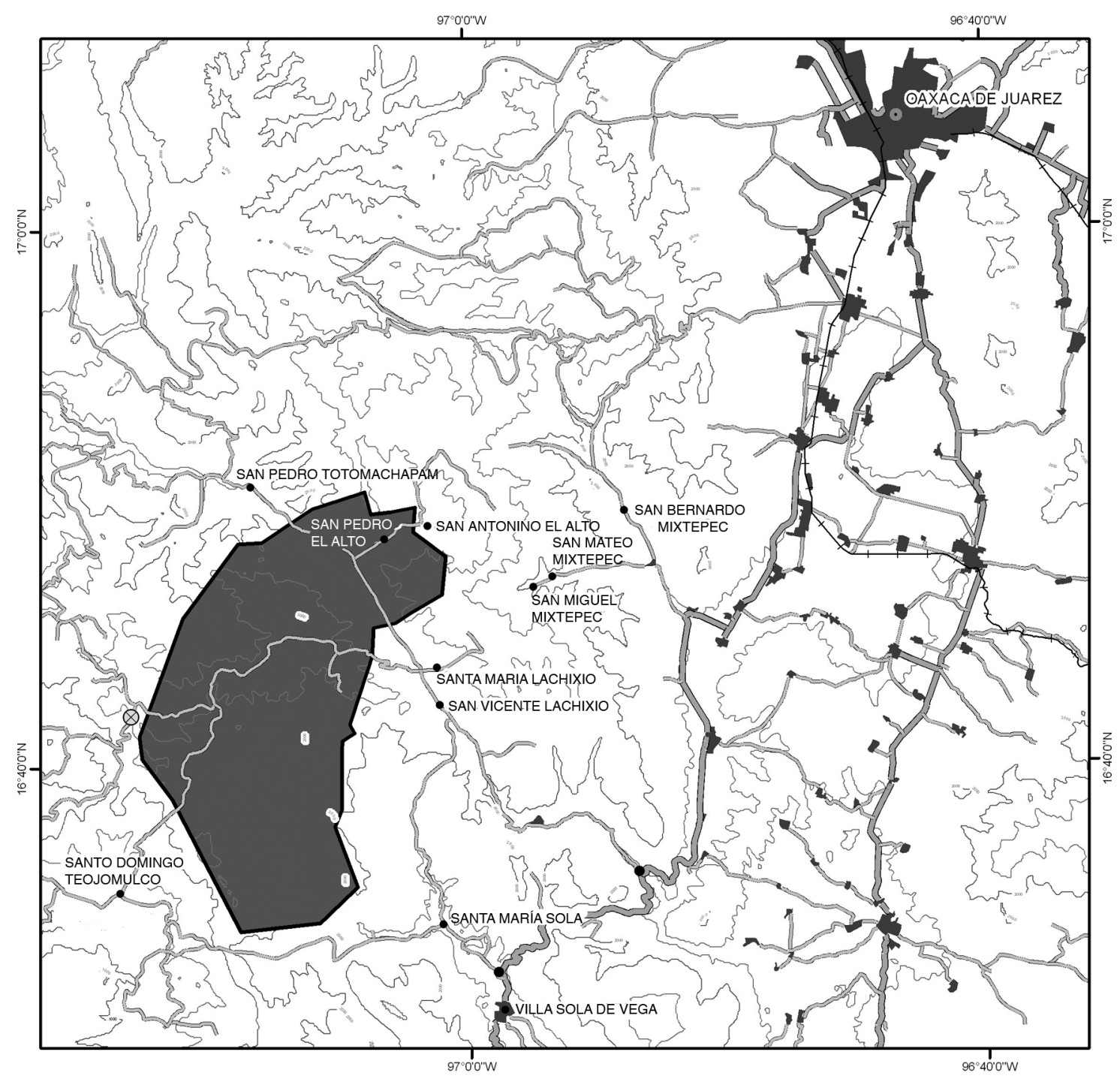

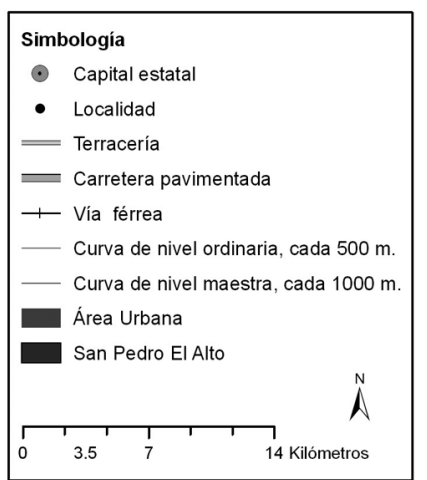

Comunidad de San Pedro El Alto, distritos Zimatlán.

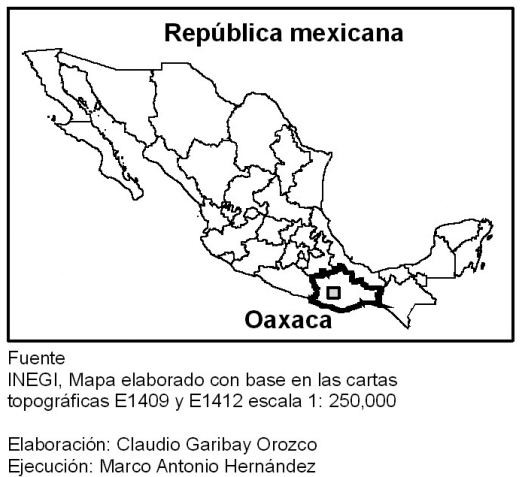


gobierna su territorio desde los márgenes de cierta autonomía social y política del Estado.

Su presente está marcado por un pasado colonial que se remonta, por lo menos, a mediados del siglo XVII, cuando formaba parte de la congregación de Lachixio, y a principios del siglo XIX, cuando se vuelve agencia municipal independiente con tierras comunales y gobierno propio. Por diversas razones históricas San Pedro pudo mantener, no sin dificultades, el control comunal de sus ricas tierras forestales hasta el día de hoy. Antes de la entrada en la región de la compañía concesionaria Aprovechamientos Forestales de Oaxaca (AFO) en 1950 — que con el respaldo del poder del político del Estado controló los bosques y pueblos de toda la Sierra Sur de Oaxaca— las familias de la comunidad de San Pedro se dedicaban a la agricultura maicera, a la ganadería familiar y al aprovechamiento de los bosques de la comunidad para usos domésticos y para la venta de madera, tejamanil y carbón a pequeña escala que se llevaba al distrito de Zimatlán o a la ciudad de Oaxaca. La economía del pueblo estaba centrada en la organización productiva del grupo doméstico y en el acceso particular de las familias a la tierra agrícola. Prevalecía un relativo equilibrio entre las riquezas de las familias, aunque existían algunas tendencias de acumulación en algunas de ellas inclinadas a la cría de ganado menor, problema que la comunidad resolvía imponiéndole a la familia enriquecida obligaciones de "mayordomía" o bien, en casos extremos, socavando su legitimidad social y el acceso a aquellos recursos que fundaban su riqueza, como por ejemplo, subirles la tarifa de pastoreo en las tierras comunales. En suma, una sociedad campesina sin mayores diferencias de riqueza y clase social, ni cruzada por distinciones de orden étnico o religioso.

A pesar del modelo económico fragmentado en unidades domésticas, las familias de San Pedro compartían entre ellas una nutrida red de reciprocidades sociales: compromisos de ayuda mutua conocidos como guelaguetzas; obligaciones de trabajo familiar hacia la comunidad llamadas tequio; obligaciones de participación en el culto religioso de los santos llamadas mayordomías; obligaciones de servicio personal al gobierno comunitario llamadas cargos; y un interés común en la defensa de las tierras comunales frente a las ambiciones de los pue- blos vecinos. En esos años San Pedro recibía pocas influencias externas y poseía un fuerte margen de autonomía política; una autonomía debida, en parte, a la incomunicación carretera que mantenía a San Pedro el Alto alejado de la modernidad y del control cotidiano del gobierno central, y también a la larga tradición de autogobierno heredada desde la época colonial.

Con el arribo de la compañía forestal se iniciaron grandes transformaciones en la vida social de San Pedro el Alto. La compañía estableció su campamento general de operaciones en el centro del territorio comunal de San Pedro, desde donde controló las operaciones forestales en terrenos boscosos no sólo de este poblado, sino también de al menos veinte comunidades similares de la Sierra Sur. A lo largo de esos años, la compañía abrió caminos, comunicó pueblos, trajo trabajadores foráneos, contrató a los pobladores locales y favoreció la monetización de la economía local y la adquisición de nuevos hábitos de consumo. Los comuneros de San Pedro aprendieron nuevos oficios: la tala industrial de árboles, el manejo de vehículos automotores, el uso de maquinaria pesada, la operación de aserraderos, la reparación de motores, la soldadura de estructuras, etc. En su condición de trabajadores los comuneros adquirieron habilidades para negociar con la empresa mejoras laborales y reivindicaciones salariales. En su carácter de comunidad aprendieron a negociar mejores contratos de venta de sus bosques y a lidiar con los discursos y las prácticas de una burocracia gubernamental que, en aquellos tiempos, ejercía una fuerte tutela en la relación entre la compañía y la comunidad.

En este periodo se dieron varios cambios culturales significativos. En apenas treinta años la comunidad perdió la lengua étnica y, en paralelo, incorporó a su cultura cotidiana valores como "progreso", "solidaridad sindical", "cooperativismo" y, sin duda, una reafirmación del discurso "nacionalista" en virtud tanto de la entrada de la educación pública formal en el pueblo como de la integración política del poblado al sistema de control político del Estado mexicano. La comunidad es incorporada al Partido Revolucionario Institucional a través de la intermediación de las organizaciones campesinas regionales, discursivamente preocupadas por procurar progreso a la comunidad y por legalizar las tierras comunales. 


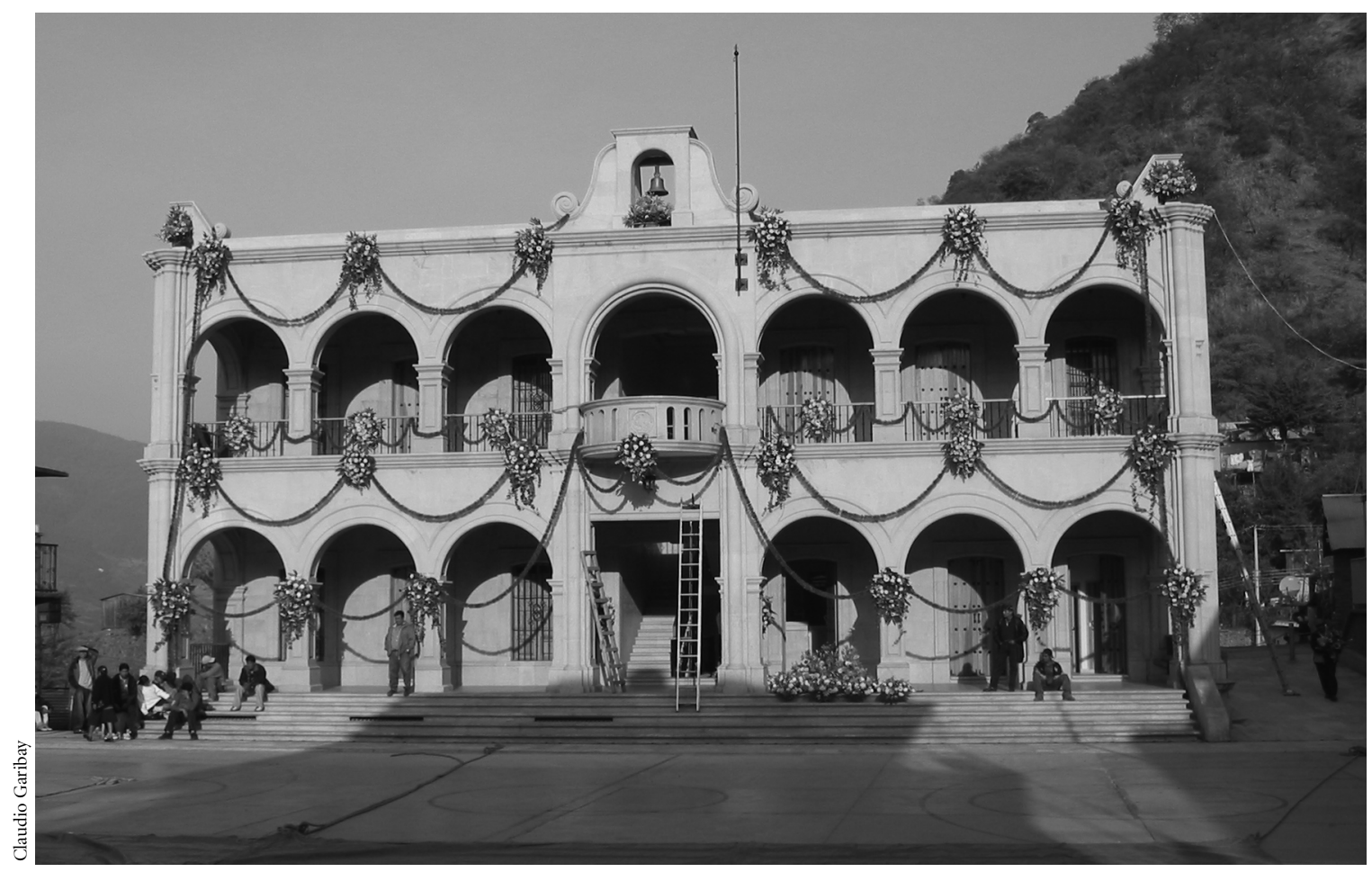

Riqueza inmovilizada en un lujoso Palacio de la Agencia Municipal.

Hacia principios de la década de 1980 San Pedro el Alto ya contaba con una experiencia acumulada. Su cooperativismo los había llevado a constituir una compañía de autobuses de pasajeros y a lograr acuerdos que obligaban a la compañía a contratar los camiones de los comuneros para el transporte de la madera que saliese de los bosques de San Pedro. La comprensión alcanzada sobre el funcionamiento de la compañía forestal y los altos márgenes de ganancia que dejaba la actividad forestal llevó a San Pedro a incrementar sus demandas. La compañía se negó a incrementar el pago de derechos de monte o a financiar el pago de obras comunitarias. Una acumulación de resentimiento llevó a los comuneros de San Pedro a organizar una pequeña revolución en contra de la compañía a principios de la década de 1980 que derivaría en el retiro de la AFO de San Pedro y de la Sierra Sur. Hacia mediados de esa década constituyeron su empresa comunal forestal e iniciaron la explotación de los bosques por sí mismos.
Si bien, en esta historia fue clave la experiencia ganada por la comunidad como trabajadores de la compañía forestal, la fundación de la empresa comunal también se debe a la asesoría y a la fuerte influencia de un bloque de funcionarios de filiación de izquierda. Estos funcionarios y operadores afines incidieron como asesores políticos en el momento de la confrontación abierta con la compañía y el gobierno federal; y posteriormente, también como ideólogos del comunalismo forestal, con el aporte de apoyo técnico y organizativo a la empresa forestal, y de habilidades políticas para captar el respaldo institucional hacia la comunidad de la burocracia. Los esfuerzos de la organización comunal y de sus nuevos intermediarios políticos llevaron a la consolidación de la empresa forestal comunal, que hoy es el centro de la vida social de esta antigua sociedad campesina.

El actual sistema de gobierno comunitario en San Pedro el Alto está compuesto por dos estructuras de autoridad: la agencia municipal, encargada del orden públi- 


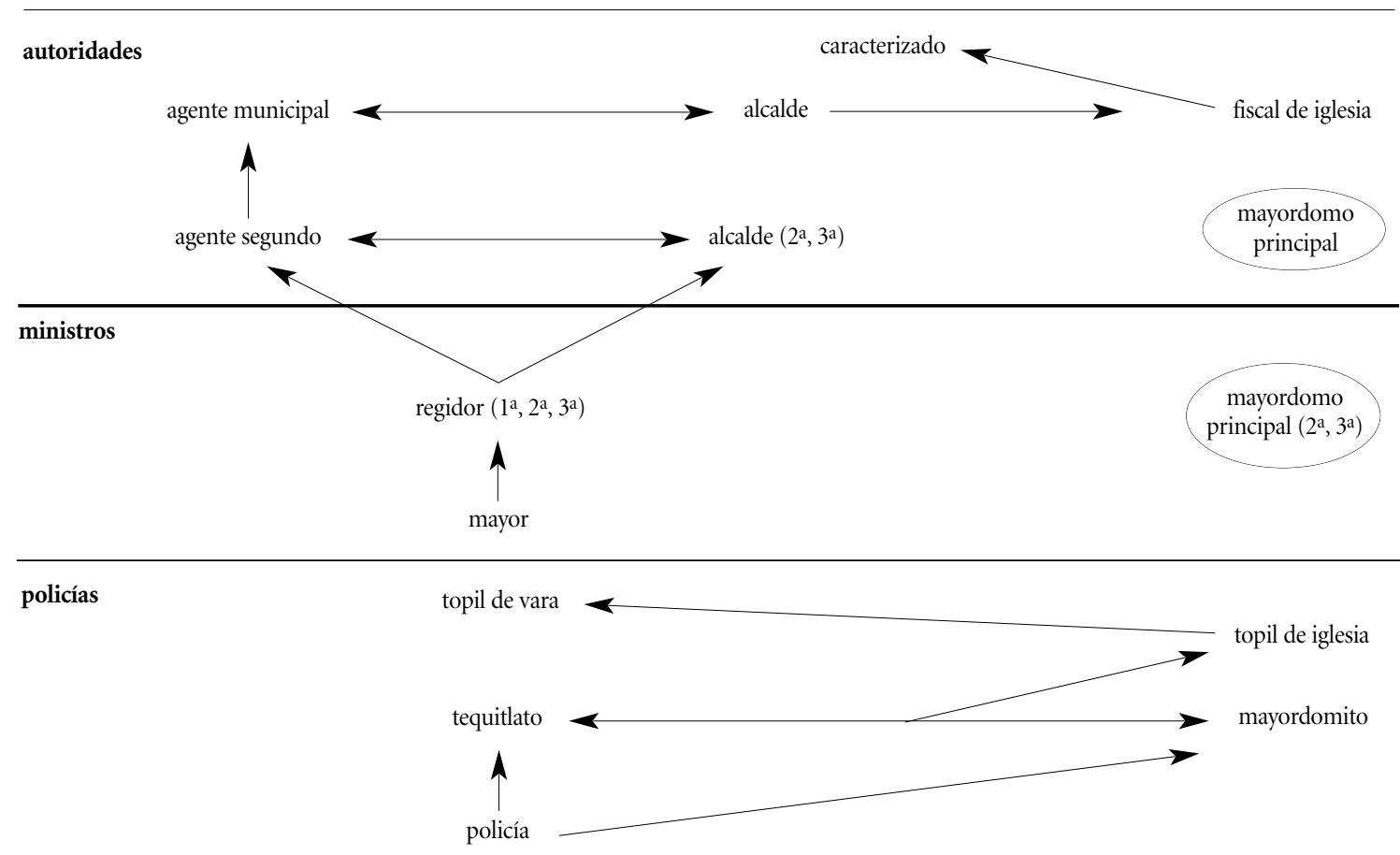

Ruta de ascenso social desde posiciones serviles a puestos de autoridad y prestigio. Cada cargo dura un año y no es remunerado. Son necesarios ocho años dados en servicio para aspirar a un puesto de autoridad, y seis años más para llegar a ser un respetado anciano caracterizado.

co, del juicio sobre riñas y pleitos, del mantenimiento y la administración de los servicios públicos, de la organización de las celebraciones cívico-religiosas, y de la representación de la comunidad - en su calidad de gobierno local- ante los poderes del Estado; y el comisariado de bienes comunales, encargado de mantener la integridad del territorio comunal, de gobernar los derechos de uso de los bienes comunes en el caso de los individuos y las familias, y de controlar el aprovechamiento de los recursos territoriales. Ambas estructuras de autoridad son controladas por la asamblea comunal, de carácter deliberativo, que mensualmente se pronuncia en torno a los asuntos de la comunidad y legitima el desempeño de las autoridades comunales.

Si bien la asamblea comunal aparece como un espacio deliberativo en el que todos gozan del mismo derecho al ejercicio de opinión, en realidad es un espacio que congre- ga a individuos altamente diferenciados entre sí conforme a un complejo sistema de rangos sociales - denominado por los antropólogos como sistema de cargos, de tal modo que, por ejemplo, una opinión cuenta, en el ánimo de la asamblea comunal, no sólo por la opinión misma sino especialmente por la jerarquía de quien la pronuncia. El sistema de cargos en un sistema institucionalizado de prestigio social está basado en el principio del servicio a la comunidad. Cada hombre miembro de la comunidad debe, a lo largo de su vida, ascender en la escala de rangos, desde aquellos de carácter servil hasta los de autoridad. Ascender en la escala conforme a la edad del individuo representa una acumulación de prestigio; no ascender representa desprestigio. Los cargos son obligatorios, no remunerados, de tiempo casi completo e insertos en una jerarquía de mando en la que el subordinado de rango inferior obedece al de rango superior. 
Estructura de autoridad en San Pedro El Alto

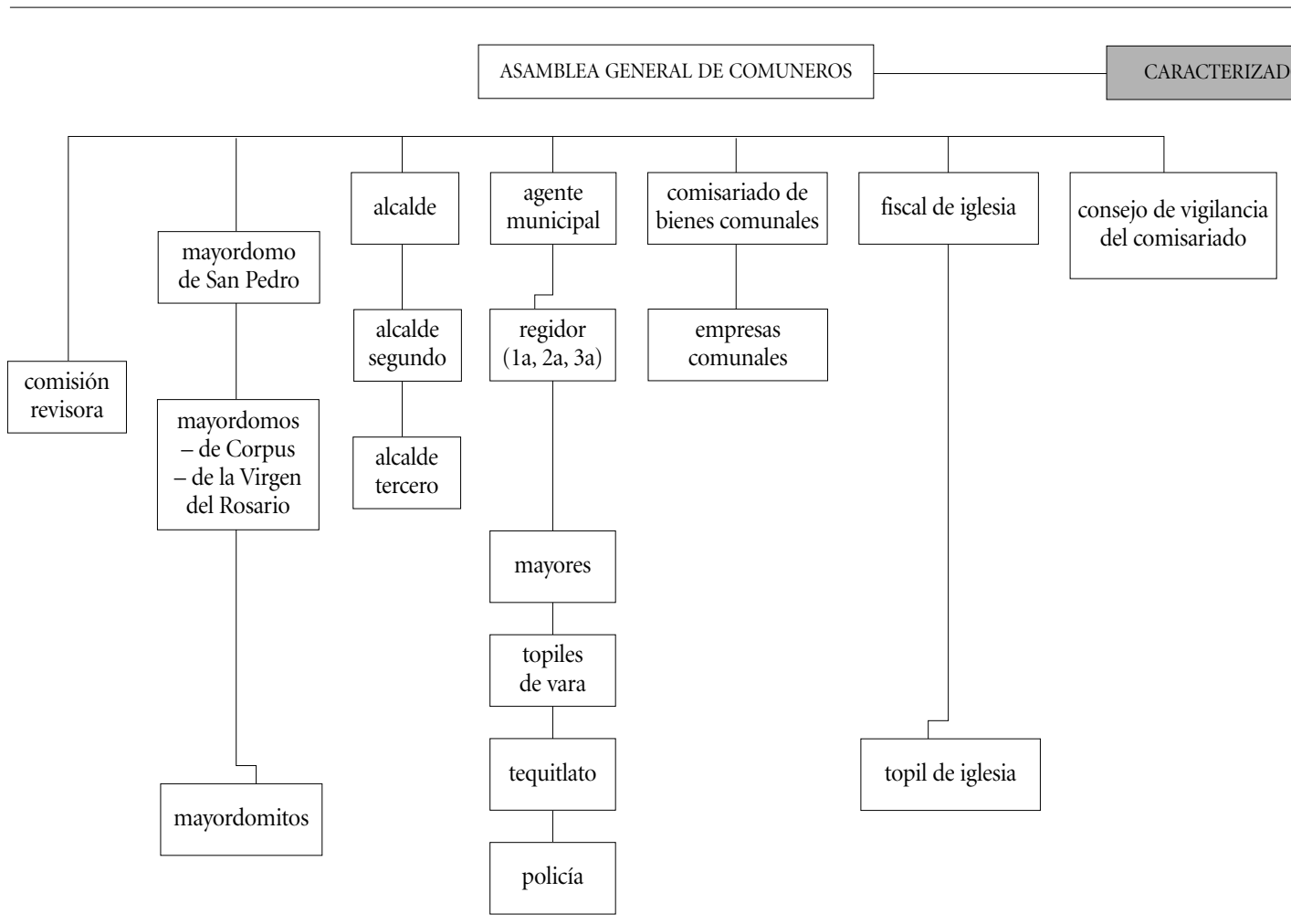

Nadie se escapa. Todos los pobladores están comprometidos con la jerarquía de mando y obediencia. Los puestos de autoridad tienen similar jerarquía, forma e independencia entre sí. Ello deriva en una mecánica de equilibrio entre los "hombres fuertes" que evita la potencial captura autocrática de la Asamblea General de Comuneros.

Sólo aquel que cumple con los cargos serviles (policías, topiles, comandantes, mayores, etc.) y los cargos religiosos (mayordomías de santos menores y mayores) puede aspirar a cargos de autoridad (regidores, alcaldes, agentes municipales, comisariado) y a posiciones de responsabilidad dentro de las empresas comunales.

Sin embargo, a pesar de esta estructura jerárquica, el modelo político comunitario pareciera diseñado para evitar la concentración de poder, en virtud de que en la escala más alta de autoridad los mandos son de igual jerarquía y diferente función. El agente municipal (función ejecutiva) es de igual rango que el alcalde (juez), al igual que el comisariado de bienes comunales (tierras), y que el fiscal de iglesia (encargado del culto). A quienes ya han cumplido con sus cargos se les define como "caracterizados" y su opi- nión tiene mucho peso. Además, la asamblea cuenta con dos instancias de vigilancia separadas que dan cuenta directa a la asamblea: el consejo de vigilancia, que se dedica a revisar las cuentas del comisariado de bienes comunales, y la comisión revisora, nombrada especialmente por la asamblea para revisar e informar en las sesiones de la misma sobre el estado de las cuentas de las empresas de la comunidad. El principio de vigilancia mutua es una práctica institucional, cotidiana, incluso exacerbada.

La empresa forestal logra extracciones anuales de 35000 metros cúbicos de madera en rollo, de los cuales unos $20000 \mathrm{~m}^{3}$ son hechos tabla en el aserradero comunal. Ello les significa - a pesar de su productividad deficiente-ingresos que alcanzan, al menos, veinte millones de pesos anuales. Las operaciones forestales de la empresa 
comunal están planeadas a largo plazo. Tienen diseñado, mediante su "Plan de manejo forestal", el destino de su territorio con un alto grado de detalle (áreas de corta, conservación, restauración, agrícolas, etc.) y definidas la multiplicidad de tareas que cumplen concienzudamente en el bosque a lo largo del año, todos los años. En el bosque cuentan con campamentos acondicionados con los servicios necesarios para los trabajadores (en su mayoría los mismos comuneros), con un sistema de radiocomunicación e incluso con una ambulancia especializada para responder a emergencias. Han adquirido en propiedad comunal activos asociados a la explotación forestal, tales como grúas de extracción y carga, camiones para transportar madera en rollo - en su mayoría propiedad de comuneros en lo particular para servicio de la empresa, buldózers, motoconformadoras y camiones de volteo usados en el mantenimiento de caminos. También tienen instalado un aserradero comunal, actualmente en fase de modernización, con el que pretenden aumentar el volumen y la calidad de la madera aserrada, con lo cual elevarán considerablemente los ingresos de la empresa.

Además, la comunidad posee una central camionera en el centro de la ciudad de Oaxaca y una flota de 14 autobuses de pasajeros que dan servicio en el tramo OaxacaSan Pedro el Alto, y en otras rutas que cubren la región. También han instalado una moderna embotelladora de agua potable de manantial en los bosques de la comunidad —operada por mujeres del pueblo—, que distribuye en la ciudad de Oaxaca, y algunos otros negocios comunales de menor calibre. El número de empleos permanentes generados por estas empresas se ubica entre 300 y 350 . En ocasiones algunos puestos quedan vacantes y tienen y que ser completados con trabajadores de poblaciones vecinas.

El control técnico del bosque se corresponde con un riguroso control político territorial. No existe tala clandestina interna o externa ni usos no permitidos por la asamblea comunal. En una región como la Sierra Sur de Oaxaca - lugar de históricos conflictos territoriales entre comunidades- los de San Pedro el Alto recurrentemente realizan actos simbólicos de posesión territorial en las fronteras conflictivas de su predio comunal. Año con año cientos de comuneros se desplazan a las orillas conflictivas para sembrar al borde del bosque fronterizo algunas pequeñas superficie de maíz no mayores de cinco hectáreas. Con ese acto retan, advierten y afirman su presencia organizada frente a las comunidades adversarias.

La influencia de la empresa forestal se extiende a todos los aspectos de la vida social. El empleo directo e indirecto les permite a los comuneros un ingreso constante y relativamente alto conforme a los bajos estándares regionales. Si bien existe una escala diferenciada de salarios, las distancias entre los más bajos y los más altos no son muy grandes. Los directivos de la empresa tienen ingresos formales de no más de 7000 pesos mensuales (700 dólares), sólo un poco mayores a los que obtienen los trabajadores de monte o los del módulo de aserrío por su trabajo a destajo. La política salarial de la empresa refleja la actitud cultural de mantener una igualdad económica entre los miembros de la comunidad. Les preocupa sobremanera la acumulación de poder económico en pocas manos. Incluso la tarifa de los fletes pagados a aquellos comuneros dueños de camiones madereros al servicio de la empresa comunal están calculadas de tal modo que los ingresos del camionero - después de descontar gastos- se ubican en un rango similar a los ingresos de los puestos directivos. La política de pagos de la empresa está diseñada para inhibir la desigualdad económica.

Algo similar sucede con la orientación del gasto de las utilidades de la empresa. Existe una tendencia del núcleo comunal a inhibir el beneficio particular y fomentar el colectivo; una política que parece buscar una fórmula de "comunidad rica y familias pobres". En efecto, las utilidades de la empresa son puestas a consideración de la asamblea comunal, que en deliberación decide el destino de los fondos. Dejando fuera los fondos de reinversión en la empresa forestal, las utilidades se orientan sobre todo al gasto en tres tipos de objetivos públicos: 1) en obras y servicios de beneficio colectivo; 2) administración y gestión del sistema de gobierno comunitario; y 3 ) gastos del ciclo ritual y consumo simbólico comunitario.

El primer tipo de gasto está relacionado con el financiamiento de infraestructura de la comunidad (sistema de agua potable, mantenimiento de caminos, arreglo de calles, construcción de escuelas, centro de salud, obras de infraestructura en irrigación, sistema de recepción colec- 
tiva de televisión, etc.); con el apoyo al sistema escolar compuesto por tres centros preescolares, la escuela primaria, tele secundaria y tele bachillerato; $y$ también con el mantenimiento de una especie de sistema de seguridad social comunitaria (centro médico gratuito atendido por una doctora de tiempo completo; medicina a bajo precio o gratuita; apoyo económico mensual, a manera de jubilación, a toda persona mayor de 60 años; apoyo a mujeres viudas; tienda comunal; servicio diario de transporte escolar para el traslado de los niños de las rancherías a las escuelas del pueblo, etc.). De alguna manera, la empresa de autobuses de pasajeros de la comunidad entra en esta categoría, pues el interés en su sostenimiento responde a la necesidad de los pobladores de mantenerse comunicados con la ciudad de Oaxaca, más que a las escasas utilidades que se obtienen.

El segundo tipo de gasto sostiene el pago de los viáticos de representación del gobierno comunitario (agencia municipal y comisariado de bienes comunales) para atender los asuntos y negocios de la comunidad. En virtud de que los puestos son "cargos de servicio a la comunidad", quienes están en ellos no perciben un salario, pero sí lo necesario para el cumplimiento de gestiones a nombre de la comunidad. Un interesante y complejo sistema de contrapesos y vigilancia mutua impide que la acumulación de poder político, efecto de la interacción e intermediación con poderes externos, se transforme en capital económico. En principio, nadie que llegue a un puesto de poder comunitario tiene por qué enriquecerse pues no se paga un sueldo que lo permita, de tal modo que, para el pueblo, no hay explicación verosímil que legitime la compra de un camión nuevo o una casa en la ciudad de Oaxaca. Y en el ethos comunitario no es la acumulación de riqueza económica, sino la acumulación de prestigio lo que permite el ejercicio de poder.

El tercer tipo de gasto, dedicado al ciclo ritual y al consumo simbólico, es, a nuestro modo de ver, la clave de la construcción corporativa de San Pedro. El pueblo tiene un calendario cargado de celebraciones religiosas y civiles. Entre las religiosas destacan las celebraciones de San Pedro, de Semana Santa, de Corpus, que requieren grandes gastos para el pago de adornos, música, comidas comunales, ceremonias religiosas, además de la secuencia de celebraciones de santos de menor rango. La comunidad también organiza grandes fiestas cívicas entre las que destacan la del Primero de Mayo, en que celebran el día del trabajo, y la ceremonia anual de cambio de poderes de la agencia municipal que se realiza los primeros días de enero de cada año. Tampoco dejan pasar ninguna fiesta cívica importante, como el 16 de Septiembre (día de la Independencia Mexicana), el 20 de Noviembre (día de la Revolución Mexicana) o el 10 de Mayo (día de la madre), sin organizar al menos una pequeña ceremonia y una comida colectiva. Los fondos para desarrollar esas festividades corren predominantemente por cuenta de la comunidad. A diferencia de otros pueblos indígenas de Oaxaca y del país, donde el pago de la fiesta de los santos del pueblo corre por cuenta de los "mayordomos" y sus familias, en San Pedro el Alto la comunidad paga el grueso del costo; si bien los mayordomos realizan gastos fuertes, estos son comparativamente menos onerosos que los costos de las mayordomías en otras comunidades.

Son tan importantes en San Pedro las celebraciones religiosas que, por ejemplo, los directivos de la empresa forestal semanalmente envían desde las oficinas que la comunidad tiene en Oaxaca varios paquetes de flores que entregan a los mayordomos de los santos para mantener la iglesia permanentemente adornada. Por su parte, las celebraciones cívicas suelen tener tal relevancia ritual que prácticamente se organizan con la misma ceremonialidad y esmero que las religiosas. Por ejemplo, en las celebraciones del Primero de Mayo en conmemoración de Los Mártires de Chicago — nombre con el que bautizaron la escuela primaria- organizan un gran campeonato de básquetbol y una comida colectiva a la que asisten entre mil y dos mil personas. En el programa del día siempre se incluye la celebración de una misa católica al aire libre y, en otro momento, en el bosque, la celebración de una ofrenda a los chanekes, espíritus fuertes que habitan en lo profundo del bosque. Así, en San Pedro el Alto, las ceremonias religiosas, los torneos de básquetbol, las comidas en común y los bailes son actividades que se repiten, con mayor o menor lujo, una y otra vez a lo largo del año. Todas estas festividades son financiadas por la empresa forestal. 
En un afán de exaltación comunitaria un importante volumen del ingreso se orienta a gastos simbólicos e identitarios. Hace unos años reconstruyeron la iglesia del pueblo que había sufrido deterioros por los temblores que recurrentemente se suceden en la región, lo que significó un gasto importante. En el año 2000 iniciaron la construcción de un suntuoso y monumental edificio "colonial" de cantera tallada para albergar dignamente al gobierno de la comunidad. Cuando el edificio fue inaugurado en mayo del año pasado, algunos de los comuneros decían que ahora el pueblo de San Pedro el Alto tenía "el segundo palacio más bonito después del palacio de gobierno de Oaxaca" - y quizá bajo ciertas convenciones estéticas sí tengan razón. Actualmente la asamblea comunal está debatiendo distintos proyectos para la construcción de un auditorio comunal que sirva para albergar a la asamblea comunitaria.

En contraste, el gasto orientado en beneficio a las familias es limitado. Al parecer, en la asamblea se llegó a un consenso, hoy implícito, que consiste en que todo gasto debe beneficiar a la mayor cantidad de comuneros, sino es que a todos; y ese concepto de beneficio público no incluye el apoyo a las familias desfavorecidas. Una imagen contrastante del pueblo es la que existe entre el lujo e inversión en los espacios públicos y la deteriorada con- dición de muchas viviendas; en especial las viviendas de las mujeres solteras, viudas o abandonadas de la comunidad. Pensamos que un efecto no buscado del comunalismo forestal ha sido el debilitamiento del papel de la familia como unidad económica. En el modelo fragmentado que persistía antes de la empresa forestal, era vital la organización laboral de la familia para manejar las actividades de la unidad doméstica; en ese contexto la unión de los esposos y la constitución de la familia extensa eran importantes. Hoy ya no es así, los hombres fácilmente pueden tener acceso la subsistencia sin necesidad de una familia. En la comunidad se presenta hoy una baja tasa de matrimonios formales (religioso o civil) y se han incrementado las uniones libres. Es común que entre las personas jóvenes y de mediana edad se tengan, a lo largo de la vida, varias parejas sexuales, y que las familias estén compuestas por hijos de varios padres. Hay un alto porcentaje de familias —entre 20 o $30 \%$ - de jefatura exclusivamente femenina, que son las familias más pobres del poblado; especialmente las que están en la etapa en la que sólo hay hijos pequeños. Es frecuente que esas familias se dediquen al jornalerismo agrícola en el pueblo, con pagos precarios, en el que la madre se lleva a sus hijos pequeños a trabajar en tierras de algún comunero empleado en la empresa. En San Pedro hay una fuerte exclusión

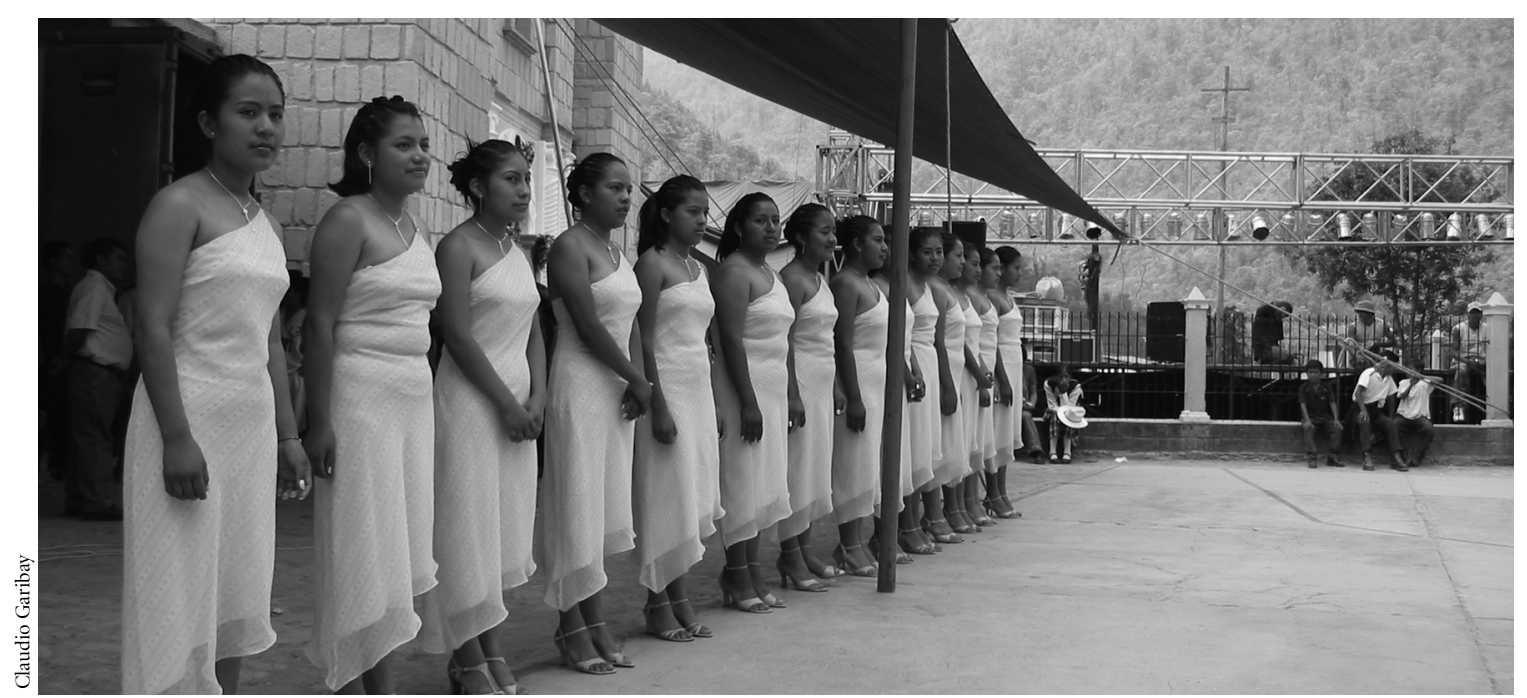

Damas de honor en la inauguración del Palacio de la Agencia Municipal. 
de género. Se asume que los hijos no son de la pareja sino de la mujer. Si bien hay disputas ante el alcalde de la comunidad, frecuentemente el hombre se desprende sin problema de responsabilidades paternas, no así la madre. Las mujeres no tienen acceso a la asamblea o puestos de poder, y eventualmente entran como trabajadoras en la empresa en posiciones secundarias. La asamblea comunal, interesada en la construcción del nuevo auditorio comunal no ha considerado la iniciativa de algunas mujeres para que se cree una guardería infantil que les permitiera contar con más tiempo para trabajar en la empresa.

La comunidad de San Pedro el Alto se desenvuelve con fuertes márgenes de autonomía ante poderes externos y frente al Estado. El suyo es un orden social que se resuelve dentro de sí mismo. Fuera de los días de fiesta, ningún forastero puede permanecer en la comunidad sin permiso explícito de las autoridades. Nadie puede vender casas o derechos sobre terrenos a personas ajenas a la comunidad. No hay presencia de partidos políticos y no se acepta el proselitismo patente a favor de tal o cual candidato en las elecciones municipales, estatales o federales; eventualmente los candidatos de los partidos nacionales pueden solicitar hablar ante la asamblea comunal y nada más. Se inhibe la presencia de misioneros protestantes y se presiona a la única familia protestante a que cumpla con las obligaciones impuestas para todos en la comunidad. De una u otra manera los comuneros están siempre comprometidos con algún servicio a la comunidad (cargos, comisiones, tequios). Faltar a la obligación comunal genera multas y arrestos. Para salir de la comunidad por meses es necesario prevenir a la autoridad y el regreso requiere de una solicitud de reingreso que se debate en asamblea. Todo esto nos presenta un caso excepcional en el que la entidad comunitaria mantiene una rigurosa disciplina sobre su población.

\section{CONCLUSIÓN. ETHOS COMUNITARIO Y RÉGIMEN POLÍTICO}

$\mathrm{Al}$ inicio de este artículo planteábamos dos preguntas. La primera era: ¿̨la permanencia social de las CFI en el contexto actual supone necesariamente la construcción de una comunidad moral encerrada en prácticas y valores sociales unitarios propios del orden social corporativo? Sin duda una golondrina no hace verano. La respuesta queda pendiente en espera de un debate en torno a un mayor número de casos ejemplares. Sin embargo, San Pedro el Alto ilustra cómo una empresa forestal industrial, con su diseño organizacional jerárquico y centralizado, se inserta en una pequeña sociedad campesina de modo que se convierte en sustento económico de las familias del pueblo, pero también en el medio por el cual se financian no sólo servicios y beneficios públicos, sino también, y en especial, el gasto en el consenso constitucional comunitario. El nutrido calendario de celebraciones religiosas y fiestas cívicas, con sus abundantes y generalizadas comidas colectivas, con sus misas, ofrendas animistas, torneos organizados de básquetbol, con la música, el baile y el festejo colectivo, pareciera, en su exceso festivo, lograr la suspensión momentánea de distancias y jerarquías y dar paso a una especie de comunidad afectiva de alcance aldeano, vinculada por creencias, sentimientos y significados compartidos. Los tequios, las excursiones de centenas de comuneros a las fronteras comunales, los desplantes de afirmación territorial, la edificación de lujosos palacios comunales, la exaltación de los logros colectivos parecieran fomentar ese mismo sentido moral dirigido hacia un "nosotros" comunitario. Hasta cierto punto, los individuos pueden disentir en pensamiento con el ethos comunitario. Hay cierta tolerancia ideológica — como lo muestra la permanencia de una familia protestante en el pueblo—; sin embargo, no se puede disentir en la activa participación en comisiones, cargos y servicios comunitarios definidos en la asamblea comunal, como lo muestra esa misma familia protestante. Hoy el modelo organizacional de la empresa forestal y la legitimidad del control centralizado de los bosques están integrados al nivel de constitución comunal. La crítica al modelo económico colectivista es impensable. La empresa forestal ya forma parte del conjunto de creencias morales que dan cuerpo al ethos comunitario. Pensamos que los fracasos de otros comunalismos forestales bien pueden tener su explicación en la incapacidad de construir un "ethos comunitario" por encima de aquellas distinciones de linaje, etnia, riqueza, 
religión, cultura, o sea, en la dificultad de construir una comunidad moral.

La segunda pregunta: ¿las CFI, en tanto que orden social constituido, tienen correspondencia directa con un régimen político autocrático, con uno democrático o con alguno de otro tipo? Al igual que la primera interrogante, tampoco puede ser contestada sin el análisis de más casos ejemplares, sobre todo porque San Pedro el Alto muestra un régimen político singular. Definitivamente no tiene un régimen autocrático o caciquil. El diseño institucional con múltiples puestos de autoridad y una rigurosa vigilancia mutua, tarea de la asamblea, pareciera conjurar el eventual peligro de captura de la institución comunal por algún grupo sostenido en el poder personal y el beneficio particular. El régimen político de San Pedro es un eficiente y sofisticado sistema de equilibrios y una singular combinación de democracia directa con un régimen de notables. Sin lugar a dudas, las decisiones se toman en la asamblea comunal, una asamblea que controla de manera efectiva a sus gobernantes y evita la construcción de desequilibrios y la concentración de facultades en personas y grupos que socaven el poder de la ecclesia. Este mecanismo de democracia directa se combina, de manera asombrosa, con un riguroso sistema cultural de jerarquías sociales, que reserva las posiciones de poder sólo a aquellos que a lo largo de su vida han reunido los méritos suficientes, que por su recorrido en la escala de rangos han alcanzado una condición de hombres "notables". San Pedro parece una combinación exitosa entre el principio de igualdad formal de los miembros de la comunidad reunidos en asamblea —ello después de la exclusión cultural de las mujeres - y el principio de distinción social que asegura el poder de los viejos por sobre los jóvenes. Del otro lado del espejo, y limitado, como lo es todo régimen de democracia directa para procesar con tolerancia el cuestionamiento de su propio ethos comunitario, también podemos pensar a San Pedro el Alto como una "dictadura de la mayoría".

Por supuesto, los procesos políticos comunitarios son fluidos. Eventualmente, una comunidad gobernada por notables puede transformarse en una democracia directa. A su vez, ésta - por crecimiento poblacional— en democracia indirecta. O bien ser capturada por un grupo caciquil e iniciar un dominio autocrático. Lo dicho aquí no es una conclusión sino un principio aún impreciso. Es un intento de presentar un conjunto de conceptos que eventualmente permitan el desarrollo de una teoría política de los ámbitos comunales. Sin duda, ello requiere cumplir dos tareas pendientes: por un lado, la discusión teórica, y por otro, el desarrollo etnográfico de casos ejemplares.

\section{Bibliografía}

Alatorre, Gerardo, 2000, La construcción de una cultura gerencial democrática en las empresas forestales comunitarias, Juan Pablos, México.

Aseteco, 2002, Una caminata de veinte años en los bosques comunales de Oaxaca, Aseteco A. C., Oaxaca.

Bray, David y Leticia Merino, 2004, La experiencia de las comunidades forestales en México, Instituto Nacional de Ecología, México.

Clastres, Pierre, 1987, Antropología política, Gedisa, México.

Garibay, Claudio, 2002, "Comunidades antípodas", Relaciones, vol. XXIII, núm. 89, El Colegio de Michoacán, Zamora, pp. 84-125.

Hardin, Garret, 1968, "The Tragedy of the Commons", Science, vol. 162, Nueva York, pp. 1243-1248.

Klooster, David, 1997, Conflict in the Commons. Rules and Around a Common Resources Management in San Miguel Peras, Oaxaca, Mexico, tesis doctoral, Universidad de California, Los Ángeles.

Mallon, Florencia, 2003, Campesino y Nación. La construcción de México y Perú poscoloniales, El Colegio de Michoacán, Zamora.

Ostrom, Elinor, 1991, Governing the Commons. The Evolution of Institutions for Collective Actions, Cambridge University Press, Nueva York.

Putnam, Robert, 1993, Making Democracy Work: Civic Tradition in Modern Italy, Princeton University Press, New Jersey.

Sabean, David Warren, 1984, Power in the Blood. Popular Culture \& Village Discourse in Early Modern Germany, Cambridge University Press, Nueva York.

Sartori, Giovanni, 1988, Teoría de la democracia. Los problemas clásicos, Alianza Editorial, Madrid.

Wolf, Eric, 2001, Figurar el poder. Ideologías de dominación $y$ crisis, Centro de Investigaciones y Estudios Superiores en Antropología Social, México. 